\title{
ConfluenCIA DE EXPERIENCIAS ETNOMÉdICAS Y USO DE PLANTAS MEDICINALES EN PRACTICANTES NATIVOS DEL VALLE DE TRASLASIERRA (Departamento San Javier), Córdoba, Argentina
}

\author{
M. CLAUDIA LUJÁN ${ }^{1}$, GLORIA. E. BARBOZA ${ }^{1}$ y GUSTAVO. J. MARTÍNEZ²
}

\begin{abstract}
Resumen: El "Valle de Traslasierra", se extiende en el faldeo occidental de las Sierras de Los Comechingones. Su característico alejamiento de las grandes urbes, se modificó cualitativamente, debido a importantes corrientes migratorias, las que han aportado diversidad a este paisaje cultural. El objetivo es caracterizar la etnomedicina y la farmacopea natural de la región. Se recurrió a métodos cualitativos y cuantitativos mediante técnicas clásicas etnobotánicas. Se evidenció una rica terapéutica ejercida por practicantes nativos con un total de 231 taxones, 676 usos medicinales y 84 familias botánicas. Se presenta un análisis de frecuencias de usos y taxones por medio de figuras de estadística descriptiva. Las familias con mayor cantidad de taxones citados y usos medicinales son Asteraceae, Lamiaceae, Fabaceae, Rosaceae y Verbenaceae. Las aplicaciones vinculadas con afecciones gastrointestinales son las más frecuentes, seguidas por neumonología y cardiología. De los taxones con mayor cantidad de usos, el $60 \%$ corresponden a especies introducidas y el $40 \%$ a nativas. Finalmente, las narrativas denotan que los practicantes nativos, a la vez de mantener vigente su hacer con base en el saber médico popular, han incorporado representaciones y prácticas terapéuticas variadas, en especial de las medicinas alternativas, conformando así una vasta farmacopea natural con múltiples significaciones y propia de contextos pluriculturales.
\end{abstract}

Palabras clave: Paisaje cultural, etnobotánica, población nativa, inmigrantes.

Summary: Confluence of ethnomedical experiences and use of medicinal plants of practitioners native to Translasierra Valley (San Javier Department), Córdoba, Argentina. The valley named as Valle de Traslasierra extends over the western mountainside of the Sierras de Los Comechingones hills. Its characteristic distance from large cities changed qualitatively due to major migration flows. This study aims at characterizing the ethnomedicine and natural pharmacopoeia in the region. We followed qualitative and quantitative methods representative of the ethnobotanical approach. We evidenced a vast and varied therapeutics exerted by native practitioners with a total of 676 medicinal uses corresponding to 231 taxa and 84 botanical families. An analysis of frequency of uses and taxa was also carried out through descriptive statistics. The families with higher number of cited taxa and medicinal use are Asteraceae, Lamiaceae, Fabaceae, Rosaceae and Verbenaceae. The most commonly found applications were those related to gastrointestinal disorders, followed by those related to pneumology and cardiology. From the taxa with the largest number of applications, $60 \%$ comprise introduced species and $40 \%$ consist of wild native species. Finally, the narratives show that native practitioners, while keeping alive practices based on popular medical knowledge, they have incorporated various therapeutic practices and representations, especially from alternative medicine, thus forming a vast natural pharmacopoeia with multiple meanings, typical of multicultural contexts.

Key words: Cultural landscape, ethnobotany, native population, immigrants.

\footnotetext{
${ }^{1}$ IMBIV (CONICET) y Facultad Cs. Químicas (Dpto. Cs. Farmacéuticas), UNC. CC 495. 5000. Córdoba

${ }^{2}$ IDACOR (CONICET) - Museo de Antropología, UNC. H. Yrigoyen 174. 5000. Córdoba *clujan@imbiv.unc.edu.ar
} 


\section{INTRODUCCIÓN}

En Argentina, a pesar de que la medicina oficial (MO) o biomedicina es la única opción médica institucionalmente legitimada, resulta innegable su coexistencia con otras prácticas terapéuticas como las de medicinas tradicionales (MT), las medicinas alternativas complementarias (MAC) y las curaciones religiosas, conformando, en su conjunto, un sistema etnomédico (Idoyaga Molina, 2003). Las deficiencias en los sistemas de salud, constituyen un problema con diversas aristas, y tal como lo señala la OMS (2008) en sus informes, la biomedicina o medicina oficial plantea una atención fragmentada, una oferta médica muy especializada, una administración de los medicamentos no exenta de efectos secundarios, situación que con frecuencia se traduce en la pérdida de confianza en sus profesionales o en los servicios de atención primaria que ésta ofrece. Una consecuencia de ello, aunque no la única explicación, es una mayor disposición de la población hacia las medicinas no oficiales a nivel de países desarrollados (OMS, 2014). Esta situación conlleva la necesidad de contar con estrategias y políticas de accesibilidad, eficacia y seguridad para su implementación, ya que estas otras medicinas carecen de los marcos regulatorios a los que se encuentran sometido el sistema oficial de salud y de control de medicamentos. Asimismo y en relación con las plantas medicinales, se han incrementado los riesgos por la tendencia a la automedicación y la percepción de los consumidores de que los remedios herbolarios tradicionales son siempre seguros y libre de efectos secundarios (Oliveira Abreu et al., 2015). Otro de los desafíos en este sentido, lo constituye la búsqueda de la interculturalidad en salud y de la complementariedad terapéutica, con la participación y diálogo de los diferentes actores y escenarios que forman parte del sistema etnomédico de las poblaciones locales (OMS, 2008; Hilgert \& Gil, 2008; Hilgert, 2009).

La compleja trama de medicinas que caracteriza nuestro sistema etnomédico, permite pensar también en la existencia de un amplio espectro de saberes y prácticas vinculadas con el uso de las plantas, fruto de la concurrencia de diferentes experiencias y prácticas culturales. En este sentido, junto a la vigencia de las medicinas tradicionales, se observa, a nivel de países y también en Argentina, un interés creciente en las terapias conocidas como Medicinas
Alternativas Complementarias (MAC), según lo señalan los documentos de la OMS (2014).

Según el National Center for Complementary and Alternative Medicine, en los Estados Unidos, el uso de MAC alcanza en adultos a un $62 \%$, y a la vez se señalan más de 1500 artículos publicados en la temática en las bases de datos MEDLINE (Ernst, 2000). En particular, y en lo que concierne a investigaciones de etnobotánica médica y etnomedicina referidos a las MAC, encontramos, las revisiones de Barry (2006) y Quave et al. (2012). Otros estudios del mismo tenor, dan cuenta de: las transformaciones en las medicinas tradicionales en el contexto de pluralismo cultural y de migraciones urbano-rurales (Oliveira Abreu et al., 2015); de nuevas configuraciones de las farmacopeas foráneas de migrantes a partir del contacto con las nativas (Pieroni \& Quave, 2005; Ceuterick et al., 2008; Pieroni et al., 2012); del influjo de los medios de comunicación y la globalización en las farmacopeas locales (Pochettino et al., 2008); de la conformación de un sistema híbrido entre la biomedicina con las medicinas tradicionales (Medeiros et al., 2012; Hilgert, 2009), entre otros aspectos.

En nuestro país, un estudio mostró que alrededor del 55\% de los pacientes adultos encuestados había empleado en algún momento MAC (Hilgert, 2009). Dentro de las terapias empleadas por pacientes adultos del hospital de Clínicas de Buenos Aires, por nombrar un ejemplo investigado, un $36,7 \%$ eligió usar hierbas medicinales y un $11,6 \%$ flores de Bach (Franco \& Pecci, 2003), lo que ilustra el protagonismo de las plantas en este tipo de medicinas. En la provincia de Córdoba, diversidad de artículos y notas periodísticas refieren el notable interés que concitan las MAC, las que por lo general involucran una franja no despreciable de la población - en muchos casos asociadas al fenómeno New Age -o de la Nueva Era- y caracterizadas por un estilo de consumo de clases y un eclecticismo en sus prácticas terapéuticas (Carozzi, 2000). El tratamiento específico de las MAC y de las redes sociales generadas por el movimiento de la Nueva Era en Argentina, así como el rol que éstas ocupan en las trayectorias terapéuticas de sus usuarios ha sido motivo de investigaciones antropológicas y sociológicas, siendo los trabajos de Carozzi (2000) e Idoyaga Molina (2003), algunas de las principales referencias.

Para Córdoba se conocen estudios de etnobotánica médica para la población campesina de las regiones 
de Paravachasca y Calamuchita (Martínez \& Planchuelo, 2003; Martínez, 2005, 2007, 2008a, b; Arias Toledo et al., 2007), del Departamento Tulumba (Arias Toledo, 2006; Menseguez et al. 2007), las sierras de Comechingones (Goleniowski et al., 2006) y el Oeste de la provincia en la región del Chaco Árido (Trillo et al., 2010, 2014).

Asimismo existen importantes recopilaciones de la flora medicinal de Córdoba (Barboza et al. 2006) y del sur de la provincia de Córdoba, en el Dpto. Río Cuarto (Núñez \& Cantero, 2000), junto a otros informes técnicos para la región de Sierras Grandes y Traslasierra (Lagrotteria et al., 1986; Lagrotteria \& Toya, 1987; Lagrotteria \& Affolter, 1999). En contraste, no se conocen hasta el momento tanto para nuestro país como en la provincia de Córdoba- investigaciones de carácter etnocientífico que incluyan prácticas provenientes de las MAC, un fenómeno creciente en contextos urbanos y de neo-ruralidad, particularmente entre pobladores de élite (Douglas, 1998). En este sentido, este trabajo constituye uno de los primeros esfuerzos en el país destinados a poner de relieve, en el marco de un trabajo etnobotánico, el influjo de las MAC y las tensiones y síntesis que se dan entre el ámbito urbano y rural en el marco de un pluralismo médico vigente.

La complejidad social implicada en el uso de estas medicinas, la diversidad de escenarios, actores y experiencias terapéuticas que implican el empleo de plantas en la postmodernidad, y los diferentes modos de apropiación y uso de los recursos vegetales en estos contextos, ponen de relieve la necesidad de abordar este estudio desde la perspectiva interdisciplinar de la etnobotánica. De esta manera proponemos como objetivo, caracterizar el contexto de las representaciones y nociones de salud y enfermedad que caracteriza a los especialistas del Valle de Traslasierra, junto a la documentación de las plantas medicinales utilizadas, sus aplicaciones y significación en el marco del pluralismo médico vigente.

El Valle de Traslasierra, área de estudio de este trabajo, se caracteriza por la complejidad cultural y diversidad de prácticas médicas y uso de plantas medicinales, influido esto por la composición diversa de la población, el desarrollo de ferias locales y del turismo. Su característico alejamiento de las grandes urbes, se modificó cualitativamente debido a importantes corrientes migratorias
(Ramallo \& Echenique, 2000; Trimano, 2014). De esta manera y vinculada a esta actividad, la población ha incrementado el número de habitantes con la llegada de inmigrantes de grandes ciudades, como Capital Federal, Córdoba y Rosario; tales inmigrantes han elegido establecerse en forma permanente por su característica típicamente serrana, dando lugar a lo que se conoce como "población neo-rural" (Trimano, 2014). El nuevo movimiento de pobladores ha hecho que los usos y costumbres de este Valle, hayan variado, debido a la mixtura que se produce entre nativos y los nuevos inmigrantes. Resulta oportuno aquí adoptar el concepto de "hibridización" o "hibridación" acuñado por el antropólogo García Canclini (2012) y aplicado por Pieroni et al. (2012) y Ladio \& Albuquerque (2014) para la etnobotánica, el que dará cuenta de la síntesis de saberes y prácticas que acontecen en torno a los aspectos culturales en contextos como el que compete a este trabajo, en los que se tensionan tradición con modernidad.

\section{Materiales y Métodos}

\section{El Valle de Traslasierra}

El trabajo se focalizó en el Valle de Traslasierra, región geográfica natural de la provincia de Córdoba, ubicada al oeste de las Sierras Grandes y al este de las Sierras Occidentales. Debido a su aislamiento hasta tiempos relativamente recientes ha tenido una densidad demográfica menor que la de los otros valles de las Sierras de Córdoba, aunque adquirió un desarrollo vertiginoso en las últimas décadas. Es así que desde los años ochenta se afincaran en la zona algunos integrantes del movimiento "hippie" así como migrantes que conformaron un importante núcleo de población neo-rural. Se trata de un área en las que resulta frecuente la explotación, recolección y uso de plantas medicinales para acopio y comercialización (Lagrotteria et al., 1986; Lagrotteria \& Affolter, 1999).

La labor de campo se realizó particularmente en localidades del Departamento San Javier, cuya cabecera es la ciudad de Villa Dolores. El muestreo abarcó las localidades de San Javier, Villa Las Rosas, Los Pozos, Las Chacras, Los Molles, Chuchira, Las Tapias y El Pueblito (Figura 1). De acuerdo a las unidades ambientales definidas por Gorgas \& Tassile (2001), este departamento se 
corresponde con las Sierras del Sur, integradas por pampas, laderas, valles y mallines como unidades de paisaje dominantes, con gran variedad de microclimas. La vegetación forma parte del Distrito Chaqueño Serrano con los pisos del bosque serrano, el matorral serrano o romerillal, y pastizales y bosquecillos de altura.

El Municipio de Villa Las Rosas, uno de los sitios relevantes de trabajo, se encuentra situado en el faldeo Oeste de las Sierras Grandes (Valle de Traslasierra) sobre la ruta provincial $N^{\circ} 14$. Los primeros habitantes de la región corresponden a pueblos nativos Comechingones que se abastecían de sembrados y cría de ganado camélido, y su sistema comercial, estaba basado en el trueque.

Respecto a Villa Las Rosas, sus comienzos se sucedieron a partir de 1762 cuando es dividida la Estancia "Los Molles" de dicha localidad. Al producirse la división, la localidad queda alejada de lo que se denomina el "Camino Real" que era paso obligado de los antiguos pobladores. El "Camino Real" unía Córdoba con San Javier, aspecto a tener en cuenta, ya que los medios de comunicación, siempre han sido un factor importante de progreso y de cambios culturales (Ramallo \& Echenique, 2000). Hasta principio de los años '80 la principal actividad económica estaba representada por la producción y comercialización del tabaco, la que actualmente decreció considerablemente, debido al retiro de las empresas tabacaleras que realizaban el acopio, la manufacturación y la venta del producto, y a desaciertos en la recolocación del mismo. Esto ocasionó, un derrumbe pronunciado de la situación socioeconómica de los pobladores del Valle de Traslasierra y de Villa Las Rosas en particular ya que ésta era el referente de mayor importancia en dicha producción.

En la actualidad, las actividades de la producción agropecuaria se concentran en la ciudad de Villa Dolores, y en menor escala, en poblaciones pertenecientes al Municipio, como son: El Valle, Los Molles y ocasionalmente el pueblo de Villa Las Rosas. La fuente principal de la actividad económica actual se centra en el comercio con diferentes rubros (incluye explotación de plantas medicinales y aromáticas), en la construcción inmobiliaria y en la industria turística. Según datos de la Secretaría de Turismo, en los últimos años ha habido importantes inversiones en hotelerías y complejos de cabañas (Trimano, 2014).

\section{Recolección y Análisis de los datos}

En la caracterización del contexto socioambiental y sanitario del área y de la población en estudio se utilizaron técnicas e instrumentos para la investigación etnoecológica, información documental y datos de observación participante (Anderson et al., 2011). En la selección de los pobladores se recurrió a un muestreo no probabilístico, intencional o muestra según propósitos, por lo que el proceso de recolección de información estuvo controlado y guiado por la teoría emergente y procuró la saturación y exhaustividad considerando la riqueza de información obtenida en los diferentes casos. Las personas participantes del estudio fueron seleccionadas en base a informantes especializados de la comunidad y/o a partir del contacto con los entrevistados mediante la técnica de bola de nieve (Bernard, 2006). Si bien existe una gran diversidad de actores sociales que configuran hoy el paisaje humano de los ambientes de sierras, se trabajó de manera particular con pobladores rurales que al presente, o en un pasado reciente presentaban un perfil socioeconómico de tipo campesino. Se escogieron entre ellos diez especialistas en prácticas de curación y en el uso de plantas medicinales, que fueran reconocidos como tales por miembros de la población local, es decir con un criterio de convalidación de pares. Éstos contaban con un corpus de saberes propios de la medicina tradicional campesina, adoptando a la vez saberes provenientes de la población foránea de tipo neorural (en particular de las MAC), dando lugar a los procesos de "hibridización" cultural a los que se hizo referencia previamente. En este contexto algunos de ellos complementaban la atención en sus espacios de consulta ofertando preparados a base de hierbas medicinales (mezclas de hierbas medicinales secas, tinturas madres, lociones, fitoterápicos), o atendiendo sus negocios, para el caso de los herboristeros. Además de la información proveniente de los diez referentes claves especialistas, se consideraron datos de entrevistas y observaciones esporádicas que aportaron información complementaria en procura de alcanzar saturación de información etnobotánica.

La interpretación de la información etnobotánica médica se realizó considerando sus dos puntos de vistas o perspectivas de análisis, desde la visión de los actores (perspectiva émica) y desde la perspectiva de la ciencia académica (perspectiva ética) (Sturtevant, 1964; Pike, 1972). 


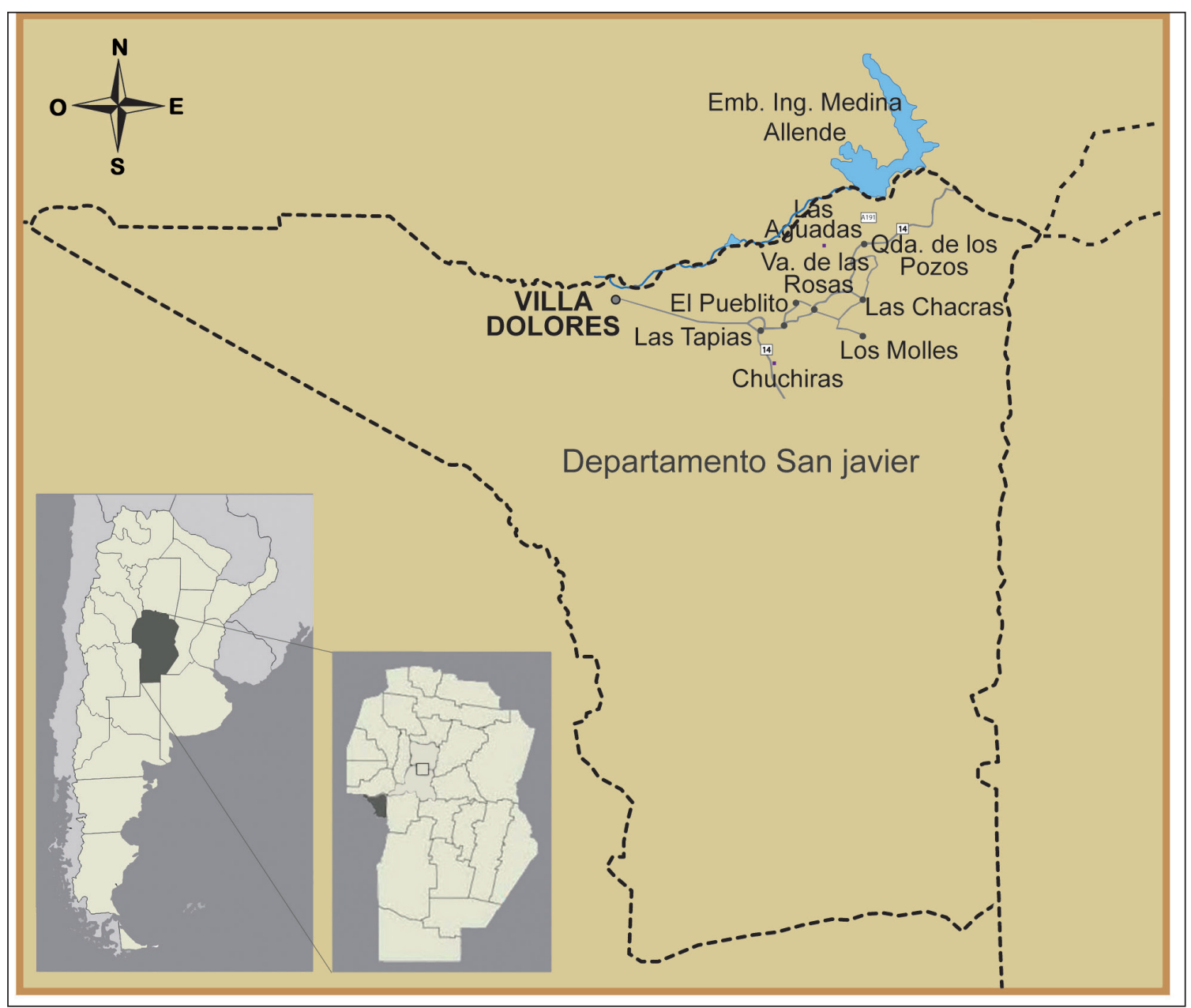

Fig 1. Área y localidades de estudio: Valle de Traslasierra, Departamento San Javier (Córdoba).

Se realizó una descripción de las principales dolencias, etiologías y tratamientos propuestos por los diferentes especialistas, los contextos y modos en los que se proveen, prescriben y/o utilizan las plantas medicinales. Para el estudio de las narrativas se recurrió a métodos cualitativos como análisis del contenido de las entrevistas en profundidad y de datos de observación participante (Guber, 2004). Los relatos escogidos se presentan en itálica indicando el entrevistador con el signo (E) y el entrevistado con guión, en los casos de diálogos.

Se registraron las fuentes de información y formas de aprendizaje de las aplicaciones medicinales más comunes en los diferentes entrevistados.
Sobre la base de la información de las encuestas semiestructuradas e información ocasional y de entrevistas abiertas se conformó un corpus de flora medicinal del área considerando las especies y material documental en cuestión. Junto con la información obtenida, y en compañía de informantes se colectaron las plantas a campo y se registraron sus nombres vernáculos. La búsqueda y recolección del material vegetal se realizó en las zonas rurales, y en algunos casos se procedió a la adquisición de material comercializable que formaba parte de las prescripciones médicas. Se procedió a la herborización a campo, secado/conservación, acondicionamiento, identificación e incorporación del material al Herbario del Museo Botánico de Córdoba (CORD). La información documental se 
registró en las bases de datos de los autores y de la colección etnobotánica de referencia del Equipo de Etnobiología (Museo de Antropología) para la provincia de Córdoba. Para la sistematización de la información de las bases de datos se incluyeron los siguientes campos: especie vegetal (categorías taxonómicas), nombre vernáculo, categorías de uso medicinal, aplicaciones específicas, propiedad terapéutica atribuida, parte utilizada, forma de preparación, forma de aplicación, cantidades administradas, grupo cultural involucrado y observaciones (Martin, 2000; Scarpa, 2012). Las aplicaciones se organizaron y clasificaron en base a categorías éticas predefinidas considerando las áreas de la salud de acuerdo con los distintos sistemas corporales.

Se realizaron gráficos para caracterizar en forma descriptiva la composición de la flora de uso medicinal, considerando frecuencias de especies y citas para el origen, estatus botánico, forma de obtención y/o recolección de las especies, familias, entre otros datos florísticos.

\section{Resultados}

\section{Actores locales}

Entre los actores convalidados por los pobladores locales, como especialistas en el conocimiento, uso y prescripción de plantas medicinales, se encuentran:

Herboristeros (HB): A cargo de comercios destinados a la venta de productos herbolarios, hierbas medicinales secas y preparados comerciales de diferente origen. En relación con el conocimiento de las plantas, ellos incorporan una rica sabiduría relacionada con su biodiversidad local, sumada a la pujante industria herbolaria local, manteniendo viva una gran diversidad de conocimientos y prácticas sobre el uso de plantas medicinales.

Practicantes de medicina casera (PMC): Presentan un claro acercamiento a las culturas modernas e incorporan elementos de la biomedicina, o bien se construye alrededor de la misma. Demuestran interés en conocer los recursos naturales y cómo aplicarlo a la salud del hombre y de los animales, y sus conocimientos por lo general, provienen de la transmisión entre generaciones. En sus viviendas resulta habitual la presencia de una gran variedad de especies medicinales cultivadas.
Especialistas en medicinas tradicionales o curanderos (EMT): Los especialistas en curación - por lo general mujeres, a las que se las refiere como "curanderas" y se encargan de la atención de dolencias "folk" que no son competencia de la biomedicina (ojeadura, pata de cabra, empacho, culebrilla, etc.). Reconocidos por sus pares y vecinos como personas comprometidas con la salud de sus pares, se les atribuye el don de la curación, y basados en saberes ancestrales, ofrecen resultados donde comúnmente "la ciencia no llega". Sólo estos informantes que poseen también una raigambre en las medicinas tradicionales (MT), son capaces de reconocer e identificar especies vegetales que ellos mismos utilizan y recetan. Por el contrario, cuando éstos poseen saberes hibridizados o eclécticos con los especialistas de las MAC, suelen adquirir las plantas en el marco de un circuito comercial que involucra herboristerías, farmacias y otros.

Practicantes de medicinas alternativas complementarias (PMAC): Por lo general se trata de personas con un mayor proceso formal de instrucción -profesionales, estudiosos, conocedores de variadas medicinas complementarias- abocados a la curación de un amplio rango de dolencias, a través de las MAC. Éstas implican no sólo el conocimiento de una medicina a base de plantas, sino el manejo de la energía u otras prácticas en las que subyace una noción de cuerpo y salud diferente al de la biomedicina y de las medicinas tradicionales. Son quiroprácticos, homeópatas, naturópatas, reflexólogos y/o acupunturistas, fitoterapistas y otras prácticas que por lo general se encuentran en tensión con la biomedicina, debido a que ésta se considera a sí misma como la única basada en evidencias. En algunos casos, se advierte también la inclusión de curaciones de tipo religiosa en manos de "maestros espirituales". A pesar de ello, la OMS (2014) considera que la eficacia o inocuidad de algunas de estas técnicas terapéuticas han sido constatadas. Los fitoterapistas (incluidos dentro de los practicantes de las MAC) consideran enfáticamente que sus prácticas de curación resultan las más eficaces en relación con las otras medicinas; conforman uno de los actores más emblemáticos de la medicina natural moderna. Hay un reconocimiento de la eficacia en el tratamiento a base de hierbas medicinales, fitoterápicos y de medicamentos de patentes. Incorporan en su vademécum un compendio relevante de especies nativas y exóticas para 
diferentes y variadas dolencias y enfermedades no folk habituales en ámbitos urbanos y/o de migrantes (por ej., estrés socio emocional, envejecimiento celular, entre otros desequilibrios psicofísicos y estéticos). En su imaginario y discurso consideran que las plantas nativas que emplean para sus tratamientos tienen sus bases en los conocimientos de los "Comechingones", aunque por lo general se trata de especies exóticas o cultivadas, en algunos casos vinculadas a la medicina oriental e hindú. En la actualidad se ha convertido en una alternativa de primera elección para el tratamiento de diversas enfermedades.

En algunos casos, encontramos practicantes en los que se hibridizan las MT y las MAC, con representaciones y prácticas mixtas. Recurren en su discurso al empleo de términos biomédicos tanto de órganos, dolencias y procesos fisiológicos. Esto es característico de esta región en la que conviven, en un mismo ámbito, grupos culturales diversos y de disímiles identidades por lo general nuevos inmigrantes o población neo-rural.

\section{Etnomedicina}

En Traslasierra, al igual que otras regiones estudiadas, se mencionan gran parte de las dolencias con caracterizaciones etiológicas y diagnósticas muy similares así como criterios terapéuticos coincidentes a las de otras áreas rurales (valor de los números, los días santos, escenas e instrumentos rituales, etc.). Esto se da entre los EMT, respecto de otros actores como los PMAC que combinan nociones y prácticas de ambos tipos de medicina. En relación con los PMAC, los entrevistados construyen sus conocimientos basados en la medicina tradicional (con especies nativas y exóticas) y la medicina naturista (que incluye especies cultivadas y aromáticas). Demuestran un buen conocimiento de las plantas, realizan sus propias medicinas caseras, aunque también recurren a la homeopatía y al curanderismo. Saben, y practican, algunas curaciones de palabra por ejemplo tratan el "mal de ojo" y "quemaduras" (según su gravedad, se repite el tratamiento varios días, por lo general se complementa con alguna planta como el Aloe y algún medicamento alopático). Algunas narrativas explican lo antes expuesto:

....en caso de resfríos, siempre se combinan "tres hierbas" en infusión, "debe ser un número impar". Pueden combinarse: Doradilla y Chañar (siempre juntos) y alternar con alguna especie que no sea "nuestra", por ejemplo el Ambay o Níspero. Los curanderos decimos, que esa tercera especie es el refuerzo

.... para tratarme el asma primero fui a la curandera y después me fui al homeópata, los dos me dieron vahos de cebolla, laurel y romero y a esta preparación yo le agregué unas hojas de níspero.....

En relación con los especialistas que combinan ambas medicinas (PMAC y EMT), se observa una mixtura de técnicas y recursos de distintas vertientes; orientalismo, medicina china, medicina popular rural, teorías sobre las energías y apoyo en imaginería religiosa cristiana. A su vez, la utilización de la "moxa", tiene que ver con la introducción de otra vertiente de saberes médicos populares, adquirido en estadías de capacitación en la ciudad de Córdoba (nos comenta el practicante), ocasión en la que incorporan conocimientos de las medicinas orientales (china e hindú). Asimismo, se consideran portadores de saberes calificados en el uso de plantas, reconociendo un amplio espectro de nativas y también foráneas. Además de las plantas de su propia cosecha, recurren a otras que adquiere en zonas urbanas como Córdoba y Buenos Aires. A lo largo de una de las entrevistas se observa también que priorizan componentes místicos y religiosos considerando que ciertos rituales como el uso de la cinta y la imposición de manos, son elementos instrumentales que vehiculizan la voluntad sanadora, lo que se refuerza con el uso de las hierbas. La presencia de la "fe" y la "confianza" en el vínculo entre el asistido y quien lo asiste, es lo que hace a la eficacia de la cura. Otras de las prácticas realizadas por uno de los entrevistados implican la "limpia" de casas, los masajes terapéuticos, el uso de aceites y esencias y la consideración de las "frecuencias vibracionales de los colores" (fundamento de la cromoterapia) como elementos que pueden usarse para la restitución de la salud.

Asimismo resulta habitual hacer una determinación sobre el origen de la enfermedad, es decir que la enfermedad "agarra" a la persona $o$ "se la agarra" la persona. En el primer caso, intervienen el "daño" y las fuerzas del mal que lo "agarran" y, en el segundo caso, es una enfermedad

La Moxa son envoltorios de hojas desecadas de Artemisia verlotiorum "artemisa" a modo de cigarros terapéuticos utilizados para calentar áreas corporales afectadas en forma localizada sin tocar la piel. Muy usada en reumatología. 
propia de la debilidad natural del individuo. Es en estas distinciones donde intervienen los conceptos de la "fe", "confianza", "don", "energía" y "capacidad" de un curandero.

.....El herpes es una enfermedad que algunas medicinas lo curan...pero por ejemplo...el herpes de la pata de cabra lo pueden curar pero solo por un tiempito...luego vuelve a aparecer, en cambio cuando lo cura un curandero no aparece nunca más.....

- (E) Siempre las curaciones suyas son... transmitiendo energía? o también con las hierbas...?

- Sí, con las manos, y también uso los yuyos.

En estas narrativas visualizamos cómo combina las prácticas curanderiles con conocimientos y elementos de la biomedicina, como también con el empleo de una vasta farmacopea en la que ha realizado una serie de combinaciones y recetas exclusivas. Las mezclas medicinales de especies exóticas con las nativas son una muestra más de un doble proceso: por un lado de un proceso histórico de síntesis en el que muchas de estas especies se han asilvestrado, formando parte de las farmacopeas nativas; por el otro la adquisición de nuevas plantas medicinales de uso en el mercado global.

La mezclapara la cistitis da muy buenos resultados. Para lavarse tiene la malva, la manzanilla, el matico, la tramontana, todo eso para lavarse cierto. Si lo hace con una sola (especie) le hace menos efecto que con otra... dándoles más cuerpo, cierto. Le hace efecto ahí nomás, "al toque". Porque sino la otra sola... igual que la manzanilla también se puede usar para varias cosas, para la vista para el estómago, para los baños... tiene mucho cuerpo de muchas cosas... Por ejemplo hay yuyos que pueden ir con muchos yuyos, por ejemplo la espina colorada; la puede usar con los yuyos digestivos, la puede usar con los yuyos diuréticos ...en varias cosas... no solo para una sola cosa.

También acostumbro recetar una especie que no es de acá con otra de acá: El "ginkgo biloba", se lo puede dar a una persona que anda flojo de la memoria, de la mente. Y bueno se puede dar el "ginkgo biloba" que se ha conocido hace poco acá, en otros lados se ha conocido antes. Y, bueno, que es para ayudar a la parte de irrigación de sangre, por ahi no le irriga buena sangre al cerebro y se siente apunado, los oídos con ruidos cosas así estoy usando la hoja y la flor, las dos cosas... a esto lo estoy mezclando con la cola del quirquincho... ayuda a la circulación y también un afrodisíaco o una especie que levanta la libido sexual... le ayuda a la memoria.

Otros informantes, manifiestan una serie de recomendaciones y amonestaciones respecto de la forma de comportarse. La salud no solamente está referida a la acción terapéutica aplicada por el curador, sino que forma parte de un conjunto de conceptos sobre la vida, el vivir correctamente, los valores, valorar y aprovechar lo que el entorno le ofrece, la responsabilidad, la conciencia, el conocimiento.

Otro aspecto de la etnomedicina es la vinculación que se establece entre lo biológico y lo anímico y la diferenciación que hacen enfermedades y curaciones para niños y adultos. Asimismo, en la descripción de las enfermedades folk ("pasmo", "aire", "mal de ojo", las "nubes", etc.) se incorporan términos de la biomedicina. Dicho de otro modo, serían transferencias de la medicina oficial a la medicina folk, pero resignificados por el marco de las MT (por ej. artritis, artrosis, reuma, colesterol, colitis, conjuntivitis, placas en la garganta, lubricación de las articulaciones, irrigación cerebral; también antibióticos, glóbulos rojos, flora intestinal, hormonas, virus, mineralización, etc.).

Las prácticas terapéuticas incluyen desde la infusión, pasando por la mezcla de hierbas, el uso de cataplasmas, fomentos, la preparación de productos animales para la curación, hasta los masajes y las recomendaciones morales o éticas para la salud.

En otros relatos se sostiene que, para complementar y reforzar la cura de palabra, ésta debe ir acompañada o "materializada" con las hierbas medicinales, asimismo a modo de diagnóstico hace una lectura con granos de trigo en un vaso de agua

Cualquier enfermedad se puede curar con la cinta, mido con la cinta, se curan también con baños.... con yuyos... En realidad no es un yuyo el que sea poderoso... por decir. no te voy a decir: "te hacés un baño de romero y se te va a ir eso" No. El baño va acompañando la curación de palabra que uno hace. Es como para reforzar lo que vos estás curando, el romero, la contrayerba y la ruda, acompañan.....

(E) Le parece que el médico tiene igual actitud?

- Noooo... vos le tenés que decir al médico que (órgano) te duele y si te duelen varias cosas, él te dice: primero curamos una parte y luego tratamos las otras. Yo trato de curarle todos los males porque si le curás uno solo, al tiempito los otros males vuelven a enfermar el sano. 


\section{C. Luján et al. - Practicantes nativos del Valle de Traslasierra, Córdoba}

Si bien la entrevistada reconoce como otra autoridad a la MO, marca una notable diferencia con las prácticas tradicionales, especialmente en las observaciones diagnósticas muy individualizadas en las alopáticas, mientras que la MT ven al hombre contextualizado, inseparable con su entorno.

Entre las dolencias atendidas por estos especialistas encontramos referencias al "pasmo", "aire", un tipo de "mal de ojo" -"conjuntivitis"-, "nube", "artritis"; éstas si bien pueden ser tratadas por los biomédicos, las vías de diagnosis y tratamientos son muy diferentes.

.... el aire y el pasmo son cosas diferentes. El aire es un golpe de aire. Te dio una puntada acá o en la espalda o en la costilla, la cintura... son esos dolores como una puntada y que se queda ahí. Eso es aire. Pero para el aire, es algo muy... como te puedo decir... es medio difícil curarlo y no tan dificil a la vez, porque vos hacés un cucurucho de diario, bien grande, le ponés unas hojitas secas de menta, lo prendés y te empezás a pasar... (por supuesto que si es en la espalda te van a tener que pasar...)

Siempre de la cintura para arriba. No del cuello para abajo. De la espalda para arriba. Que salga para arriba. Claro porque si vos te lo hacés para abajo... se te va a ir corriendo nada más y después te va doler la pierna el pie, y no vas a saber de qué. Tiene que ser siempre así. De la cintura para arriba. Y agarrás y ... si es en el cuello o en la espalda no, de la espalda para arriba ... y bueno, y como ser también, se puede hacer sahumerio de yerba (yerba mate). Vos mezclas yerba, con la hoja del coco del campo. Vos agarrás, ponés unas brasas y ponés un puñado de hojas, con la yerba, (que no sea compuesta).

Vos ponés yerba común y la hoja del coco. Hay veces que te duelen los oídos... y no es porque haiga una infección en el oído, sino que un golpe de aire, como los niños que los frecuentan los dolores de oídos a los niños! Porque es muy raro que a la persona grande le vayan a doler los oídos... pero por qué? porque los golpes de aire son más perseguidos los niños que las personas mayores. Entonces vos agarrás y ponés en unas brasitas, las hojas del coco, de la yerba y vos con ese humo te sahumás. Te ponés una toalla o algo que te cubra y te sahumás el humo. Es así. Pero te tenés que quedar un rato tapada para que no te vuelva a dar ahí nomás el golpe de aire!

.. el mal de ojo... Hay dos tipos de mal de ojos. Está el mal de ojo que es como tipo de una conjuntivitis que te agarra en la vista. Pero... una gran irritación que ahora es una conjuntivitis!. Empieza a supurar... pero antes no existía la conjuntivitis, era el mal de ojo. $Y$ después está el "ojeado". El ojeado es cuando te agarra dolor de cabeza detrás de los ojos. Eh, que te sentís mal como con "soñolencia", esa cosa fea, esa pesadez... Eso es ojeado. Eso yo lo curo de palabra, no lo curo con yuyo.

Entre las dolencias referidas como cura de palabra encontramos los "orzuelos", "empacho", "pata de cabra" y "culebrilla"; asimismo los "parásitos", "hemorroides" y las "paperas". Otras dolencias y curaciones se refieren a:

Cura de paperas: Se indica en el siguiente procedimiento "....yo curo la papera en la garganta y el pulso...... lo mismo que se encuentra en la garganta, con oraciones, lo lleva al pulso y al cabo de tres días de tratamiento, lo saca del pulso....... no tiene que mojarse ni bañarse y se toma un té bien cargado de albahaca con una aspirina para sudar las toxinas"

Cura de parásitos: Se procede al rezo el primer día, y a la mañana siguiente, se muelen 8 semillas de zapallo. Antes de las semillas se le da en ayunas, una cucharada de miel, para "llamar a los parásitos" y ahí "le manda el veneno", las semillas. A los 20 días, repite la visita y se procede a una nueva cura repitiendo el proceso. "Si a la mañana siguiente se olvida de comer las semillitas, tiene que volver a que lo cure de palabra de nuevo antes de comer las semillas, sino no sirve". Posteriormente a las semillas, a las dos horas aproximadamente, se consume algún laxante para expulsar los parásitos. En los adultos, después de la cura de palabra, se ingieren a la mañana siguiente las semillas y un vaso de ginebra en ayunas.

Curación de hemorroides: Se cura de palabra y con baños de asiento de llantén y una cucharada de sal fina, que es antibiótica. Se complementa con una infusión de llantén.

Por su parte, las dolencias y etiologías referidos por los PMAC, suelen ser más difusas y menos delimitadas en cuanto a la ubicación en un taxón específico. La noción de "desequilibrio" o la falta de "armonía" constituyen el núcleo etiológico central de estas prácticas médicas. Así, algunos entrevistados recurren a una medicina naturista que buscan el equilibrio de la salud a través de una nutrición sana (con abundantes frutas, verduras, cereales y legumbres), ejercicio, costumbres saludables, relajación y otras medidas que ayuden a promover y prevenir la salud. En lo concerniente a las terapias incorporan técnicas relacionadas a la herbolaria, ayurveda, acupuntura, iridología, reiki y el uso de las piedras, nutriéndose 
de saberes provenientes de tradiciones de oriente (del hinduismo, budismo y otras). Éstas tienden un enfoque hacia la medicina holística en la que se presta mayor atención al paciente antes que a una enfermedad específica. Asimismo, incorporan a sus creencias los poderes curativos de los materiales empleados por los practicantes nativos, a la vez, con la oración y meditación como caminos hacia la sanación.

.....lo primero es no dañar, esto es un principio sabio. El secreto está en la elección y equilibrio de los alimentos como medida preventiva de la salud. El consumo diario de cebada, lino y trigo me incorpora muchas proteinas, la estabilidad emocional la consigo con pasionaria, valeriana y tilo (lo consumo como té o en forma de gotas homeopáticas), para las infecciones de la piel utilizo la mostaza, el vinagre y frutito del quimpe. Además, voy aprendiendo de todas las plantas medicinales que utilizan los curanderos de la zona....

En particular los PMAC fitoterapistas, preparan tinturas vegetales $\mathrm{y} / \mathrm{o}$ jarabes en diferentes concentraciones según corresponda (de acuerdo con su conocimiento). Se administran de modo general, 25 gotas 4 veces por día, al inicio, luego puede disminuirse la dosis de a poco, en particular si se mezclan varias tinturas. Para la mayoría de las tinturas utilizan especies de la medicina naturista, en general exóticas, pero también las mixturan con especies utilizadas en la medicina tradicional.

\section{Caracterización de la farmacopea en el Valle de Traslasierra}

Se documentaron un total de 676 usos terapéuticos correspondientes a 231 taxones medicinales autóctonos y exóticos que pertenecen a 84 familias de plantas para el Valle de Traslasierra. Las especies introducidas cultivadas conformaron el $44,6 \%$ del total de taxones evaluados en el área rural (102 / 231), en orden decreciente se ubicaron las especies nativas silvestres, con un porcentaje del $36,8 \%$. En cuanto a las especies introducidas, adventicias o asilvestradas, se contabilizaron 35 taxones $(15,6 \%)$, que en su mayoría correspondían a especies herbáceas anuales/ bienales (20) y herbáceas perennes (9). En la última posición estuvieron las especies nativas cultivadas (3,0\%) con sólo 7 taxones de los 231 taxones contabilizados en esta zona.

De las 84 familias encontradas en el área de estudio, se muestran en orden decreciente, las 20 familias botánicas con mayor número de taxones y de usos medicinales, las cuales representan al 63\% del total de taxones y al $65 \%$ del total de usos correspondientes al área rural (Fig. 2).

En la región de estudio podemos establecer que, de acuerdo al número de taxones, las familias botánicas más representativas son Asteraceae, Lamiaceae y Fabaceae, secundadas por Rosaceae y Apiaceae. Algo similar ocurre al considerar la cantidad de usos, con la diferencia que en cuarto lugar aparece las Rutaceae (31 usos), con varias especies vinculadas a síndromes culturales o acciones simbólicas. La familia de las Plantaginaceae, más o menos a mitad de camino, presenta elementos similares en cuanto a usos y número de taxones. Si bien Gentianaceae e Hypericaceae están en uno de los extremos inferiores para el área de estudio (2 especies por familia), éstas se incluyen en la Fig. 2 ya que son muy populares con un alto consenso, como por ejemplo las dos especies de nencia (Gentianella multicaulis y G. parviflora) y el cabotoril (Hypericum connatum), respectivamente.

La Fig. 3 nos muestra aquellas afecciones o áreas de la salud que se atienden prioritariamente en el Valle de Traslasierra. Respecto al número de usos y taxones por área de salud, se posicionó en primer lugar: Gastroenterología. Otras áreas de la salud en las que resultan relevantes el empleo de plantas son Neumonología, Cardiovascular y Dermatología. Las áreas de la salud menos representadas son Oftalmología, Otorrinolaringología y Odontología. Por su parte, Parasitología, Síndromes culturales y los Preventivos presentaron pocas cantidades de taxones y usos.

La Fig. 4 muestra en orden decreciente los taxones con mayor cantidad de usos (se incluyeron aquellos con más de 4 usos). El escenario muestra un $76 \%$ de especies introducidas, mientras que un $24 \%$ son nativas. Esto se explica por la vigencia de las MAC y las farmacopeas a ellas asociadas, característica de una parte de los entrevistados. A título de ejemplo, de las tres primeras especies con mayor cantidad de usos diferentes la "manzanilla" (Matricaria chamomilla), es la mejor representada y versátil por la cantidad de aplicaciones medicinales; si a ella sumamos las siguientes especies con 10 o más usos ("limón", "romero", "melisa" y "ruda") se observa que son todas exóticas.

Las áreas de Gastroenterología, Neumonología y Cardiología están bien representadas en la mayoría de las especies; el empleo de estas dos últimas áreas está muy difundido en el ámbito de la MT, como 


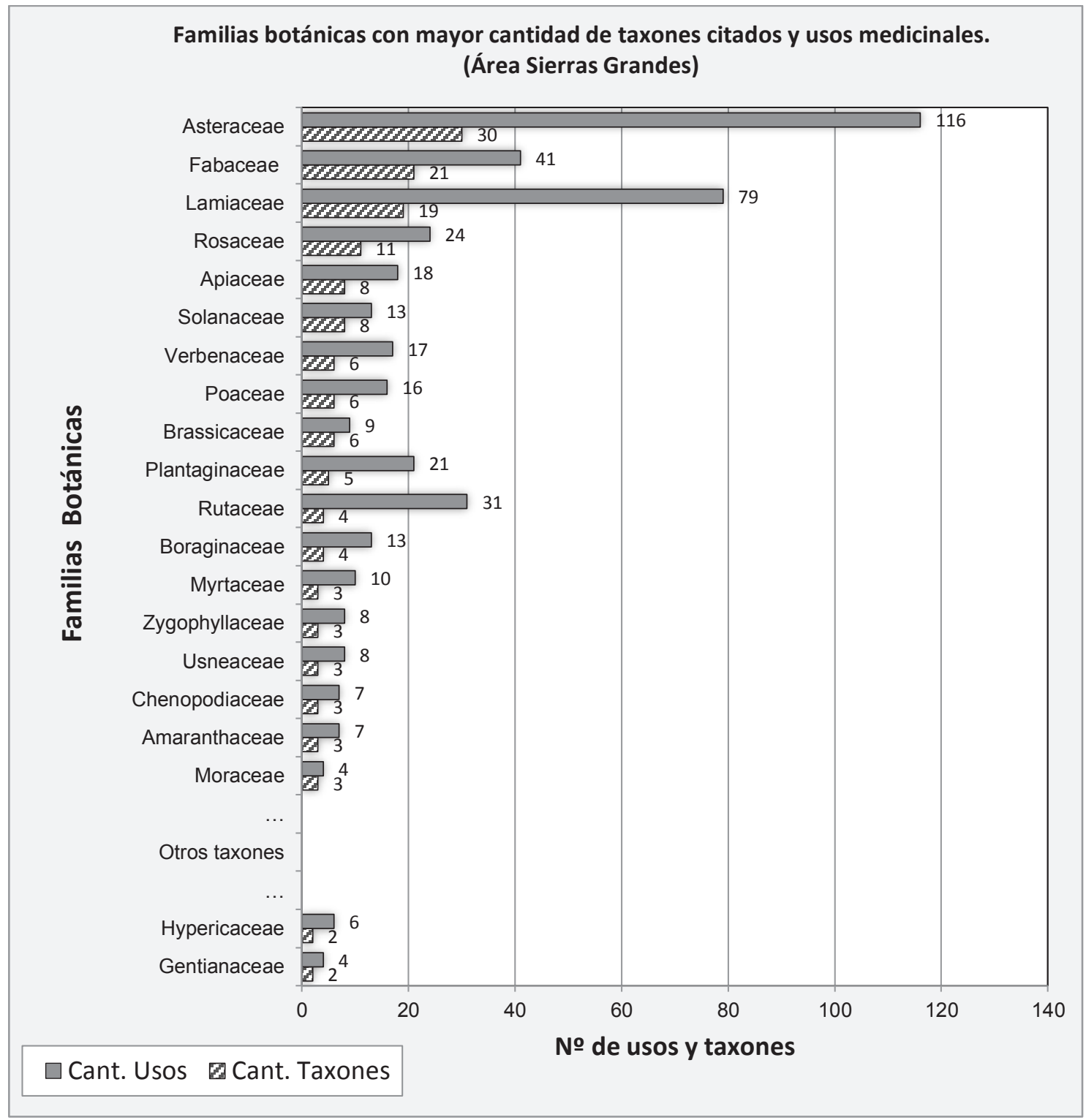

Fig. 2. Familias botánicas con mayor cantidad de taxones citados y usos medicinales.

son las afecciones respiratorias y las cardiológicas o depurativos sanguíneos.

\section{Repertorio de especies}

La Tabla 1 muestra el listado de especies medicinales con sus principales aplicaciones acorde con las categorías de uso. El detalle de recetas y preparados excede los objetivos y espacio de este trabajo, para mayor información se recomienda consultar en Luján (2015).

\section{Discusión}

En comparación con otros estudios de etnobotánica médica en contextos rurales, se observa en el Valle de Traslasierra una composición más diversificada y amplia en cantidad de taxones y usos, si consideramos los estudios de Martínez (2010) con 189 especies, Arias Toledo (2007) con 80 taxones de interés medicinal en Villa Los Aromos, Menseguez et al. (2007) con 55 especies en un paraje del Cerro 


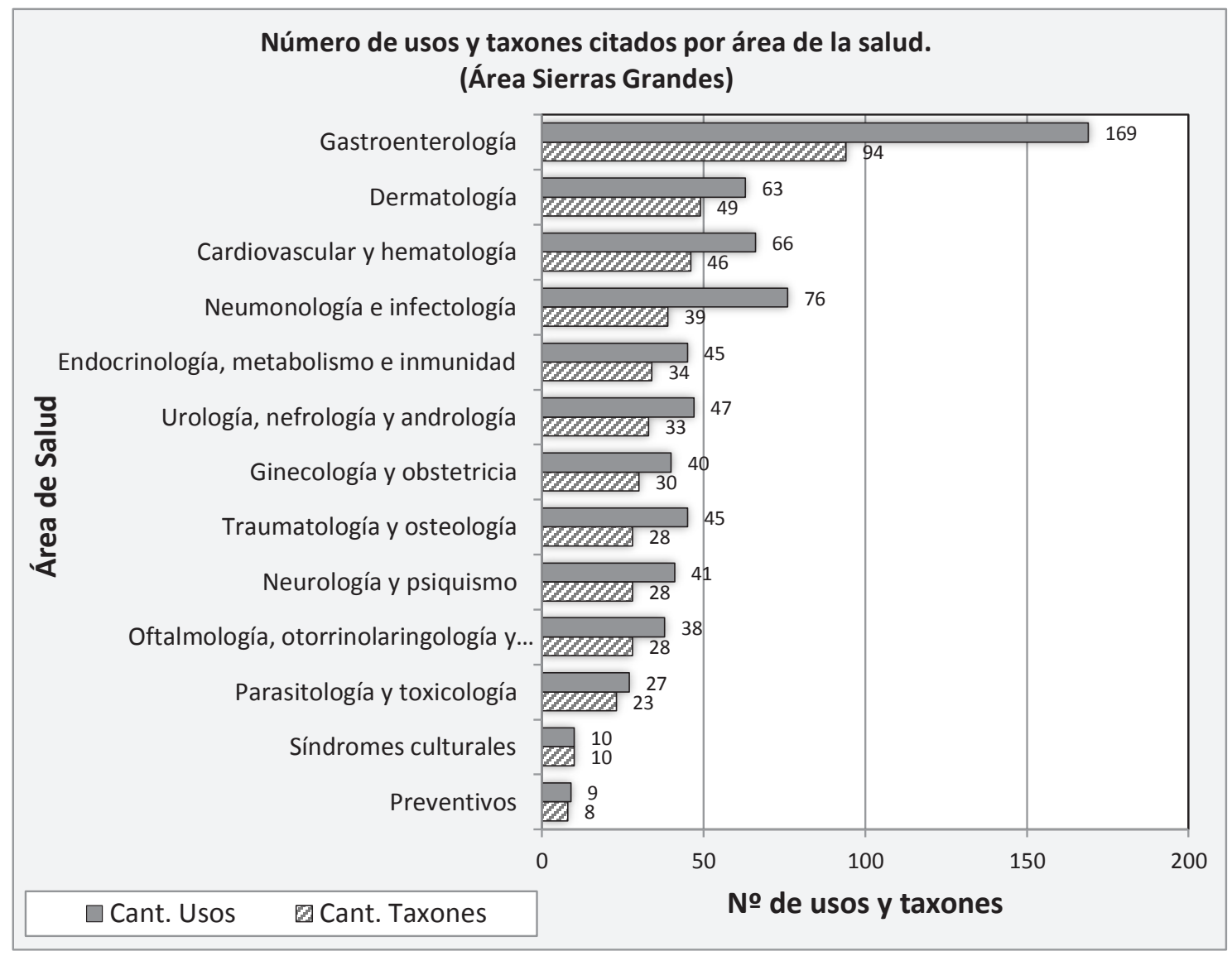

Fig. 3. Cantidad de usos y taxones citados según área de salud.

Colorado, Hilgert \& Gil (2008) con 186 taxones exclusivos en dos áreas de estudio utilizadas por los campesinos de yungas en Salta, Scarpa (2007) con 196 taxones para los criollos de Formosa, entre otros. Esto podría interpretarse en términos del muestreo de la población, ya que estos saberes fueron obtenidos de la entrevista a especialistas convalidados en la región, tanto población con tradición campesina, como pobladores que desarrollan su práctica como herboristeros y como médicos alternativos, cuya atención también es requerida. En este sentido, la amplitud de usos y taxones mencionados proviene de la diversificación de los entrevistados y de sus raigambres culturales. De esta manera se observa lo que Quave et al. (2012), señalan como naturaleza adaptativa del conocimiento local, al darse un proceso de adopción de nuevas especies y técnicas en las farmacopeas tradicionales. Estos autores ponen de relieve cómo la incorporación de especies exóticas dentro de las farmacopeas de las MAC constituye un fenómeno recurrente en toda Europa, a la vez que destacan algunos ejemplos de plantas no nativas populares como el ginseng (Panax ginseng) y el ginkgo (Ginkgo biloba), dos especies también de uso frecuente en el Valle de Traslasierra (Quave et al., 2012). Asimismo, la alta proporción de especies exóticas encontradas en la etnobotánica médica de esta región, no se debe sólo a adquisiciones recientes como las antes señaladas, sino además a la presencia de plantas incorporadas desde la colonización al repertorio de las medicinas tradicionales como si fueran propias, constituyendo así, y tal como lo señalan Hilgert et al. (2014), parte del paisaje local. Tal es el caso de especies como las mentas (Mentha spp.), lavandas (Lavandula spp.), romero (Rosmarinus officinalis), ajenjos (Artemisia absinthium), y otras comunes en las farmacopeas latinoamericanas. 


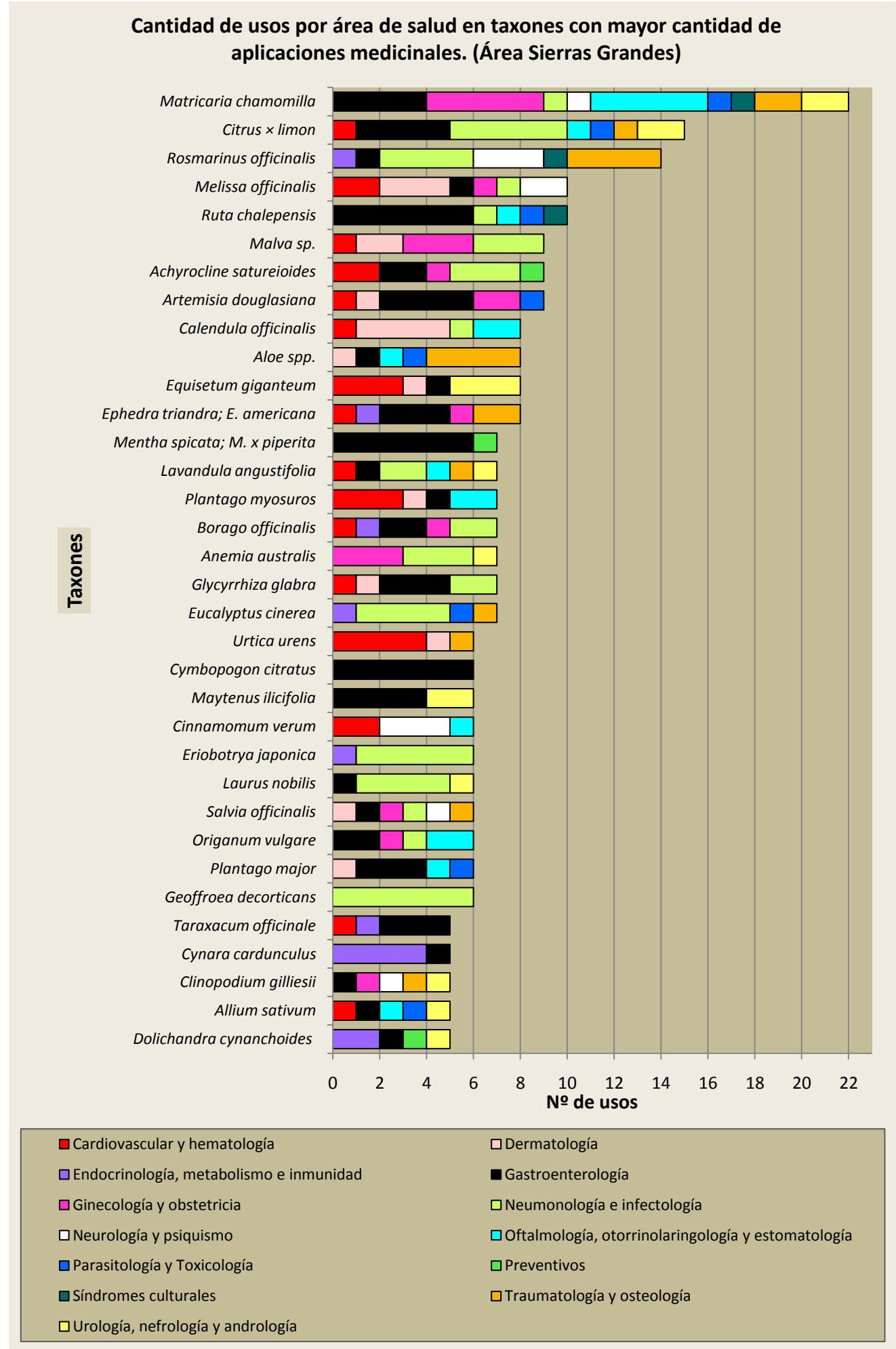

Fig. 4. Cantidad de usos por área de la salud en taxones con mayor cantidad de aplicaciones medicinales. 
Bol. Soc. Argent. Bot. 52 (4) 2017

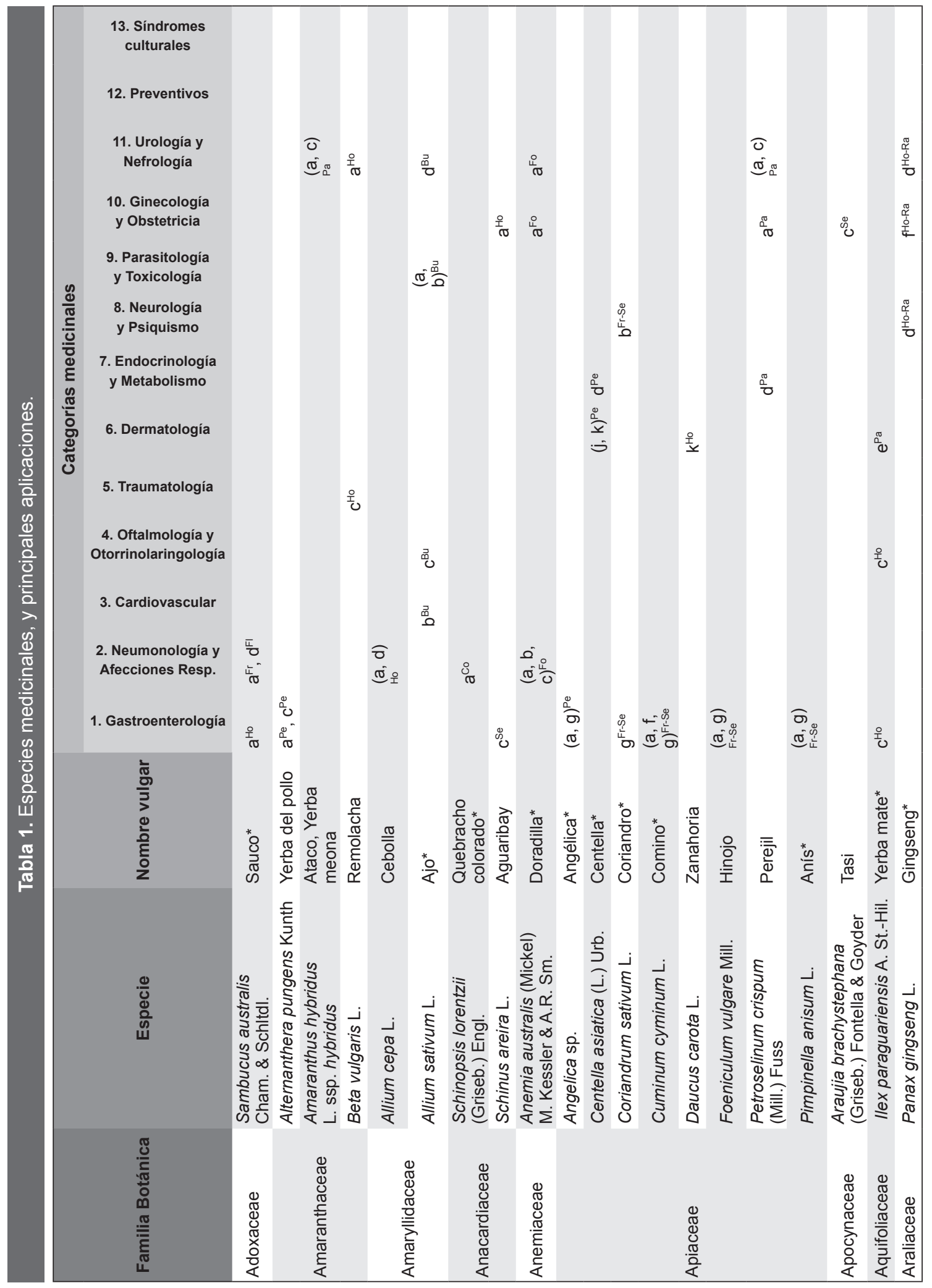


M. C. Luján et al. - Practicantes nativos del Valle de Traslasierra, Córdoba

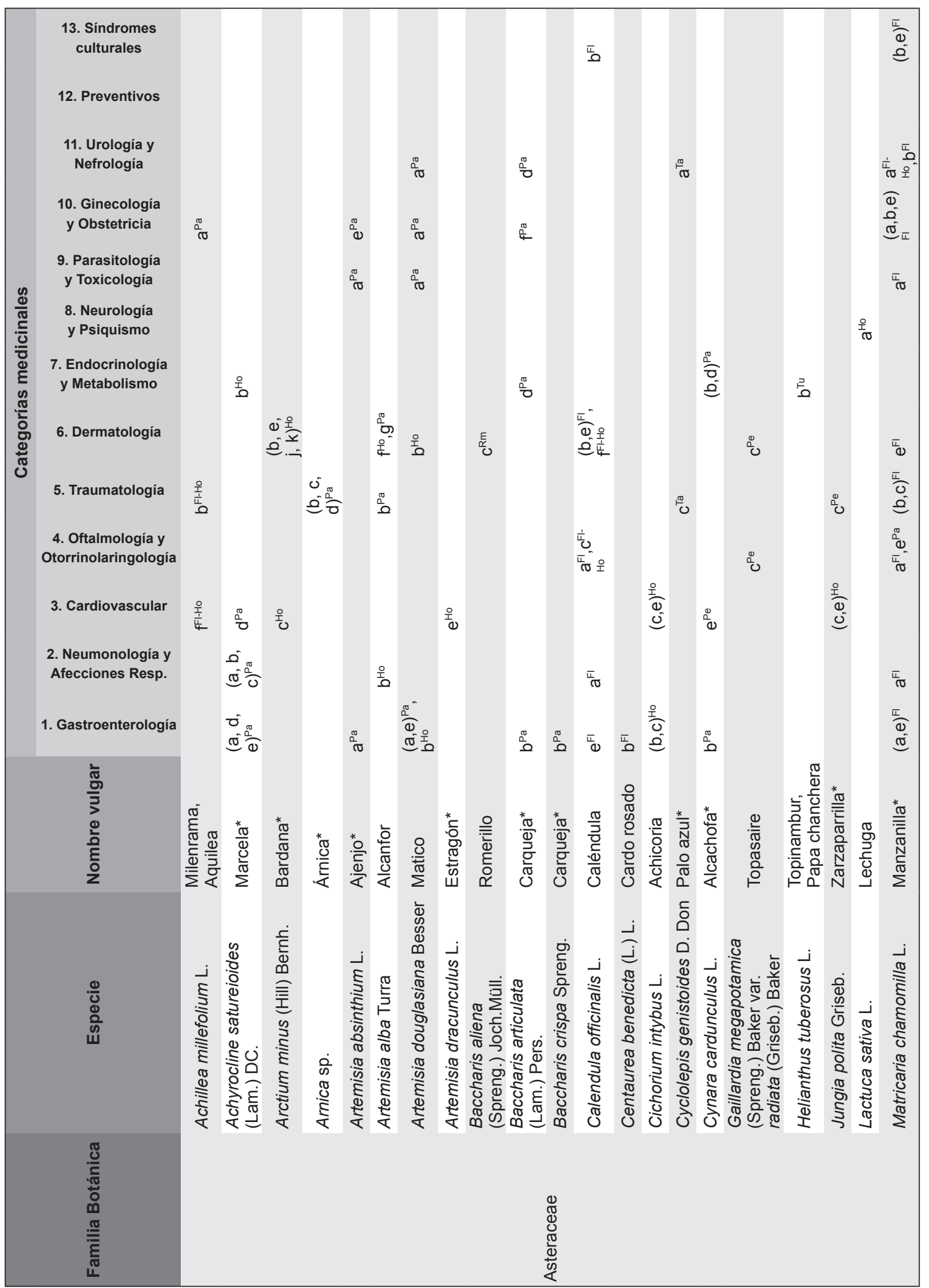


Bol. Soc. Argent. Bot. 52 (4) 2017

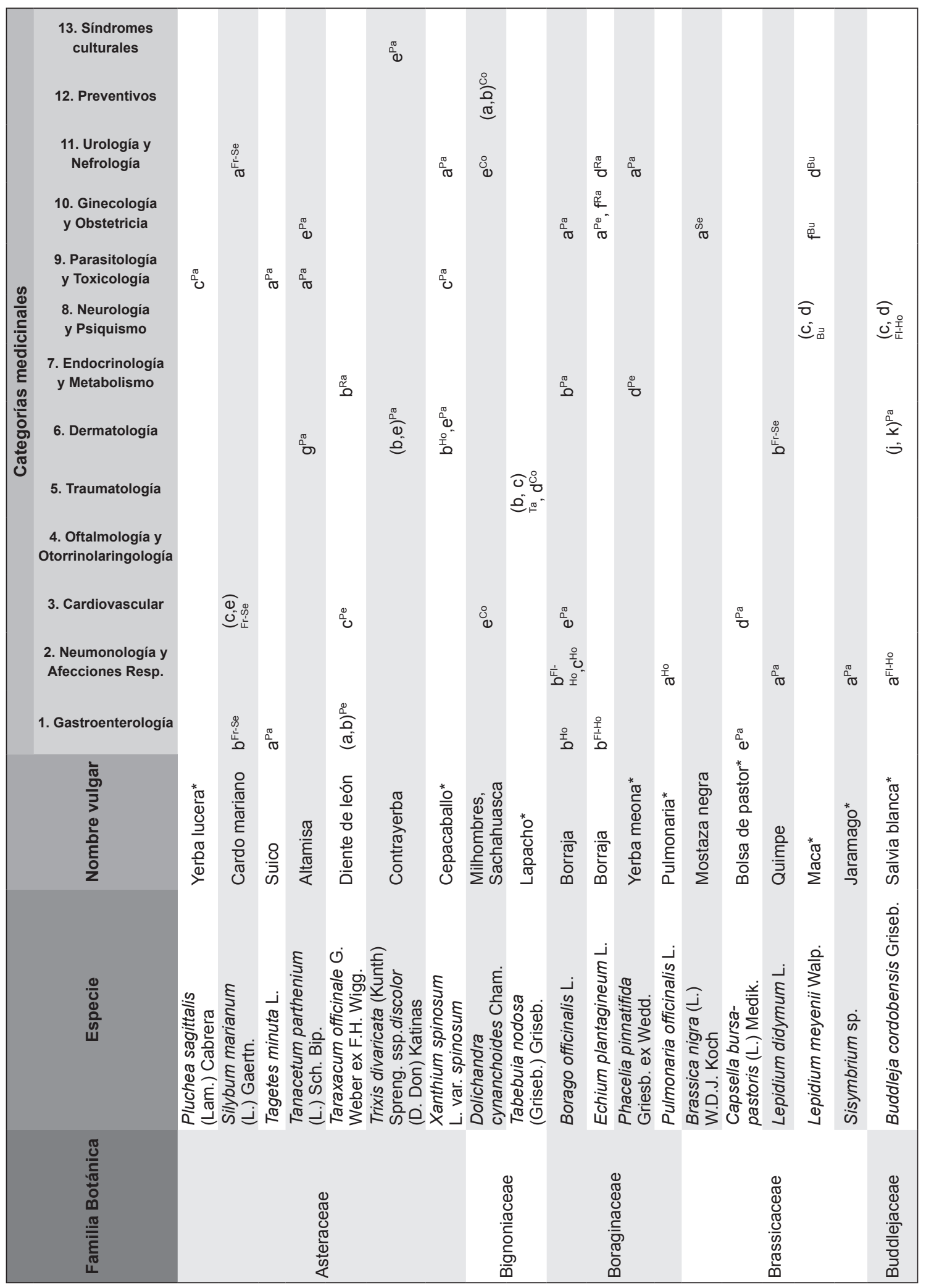




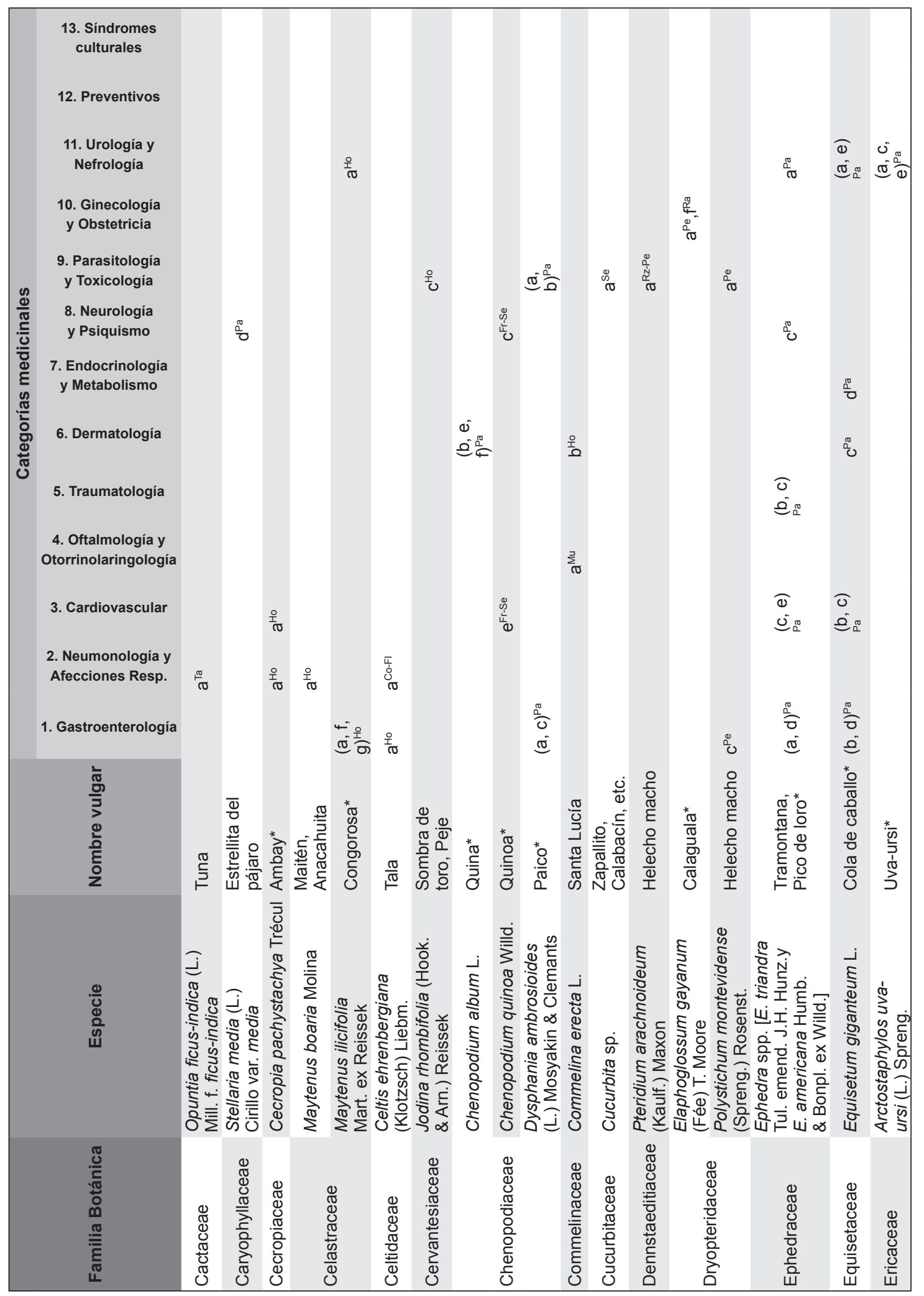


Bol. Soc. Argent. Bot. 52 (4) 2017

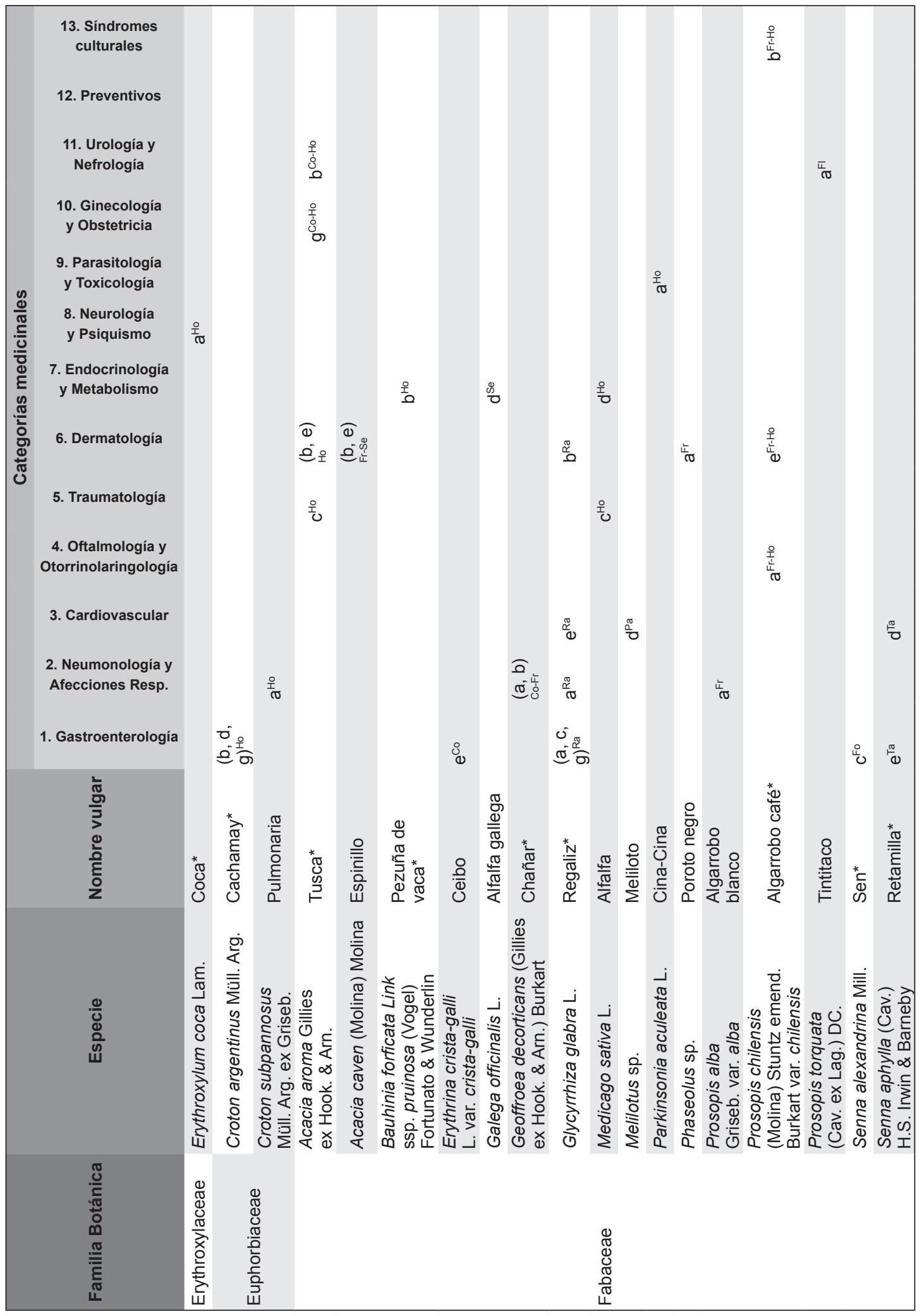


M. C. Luján et al. - Practicantes nativos del Valle de Traslasierra, Córdoba

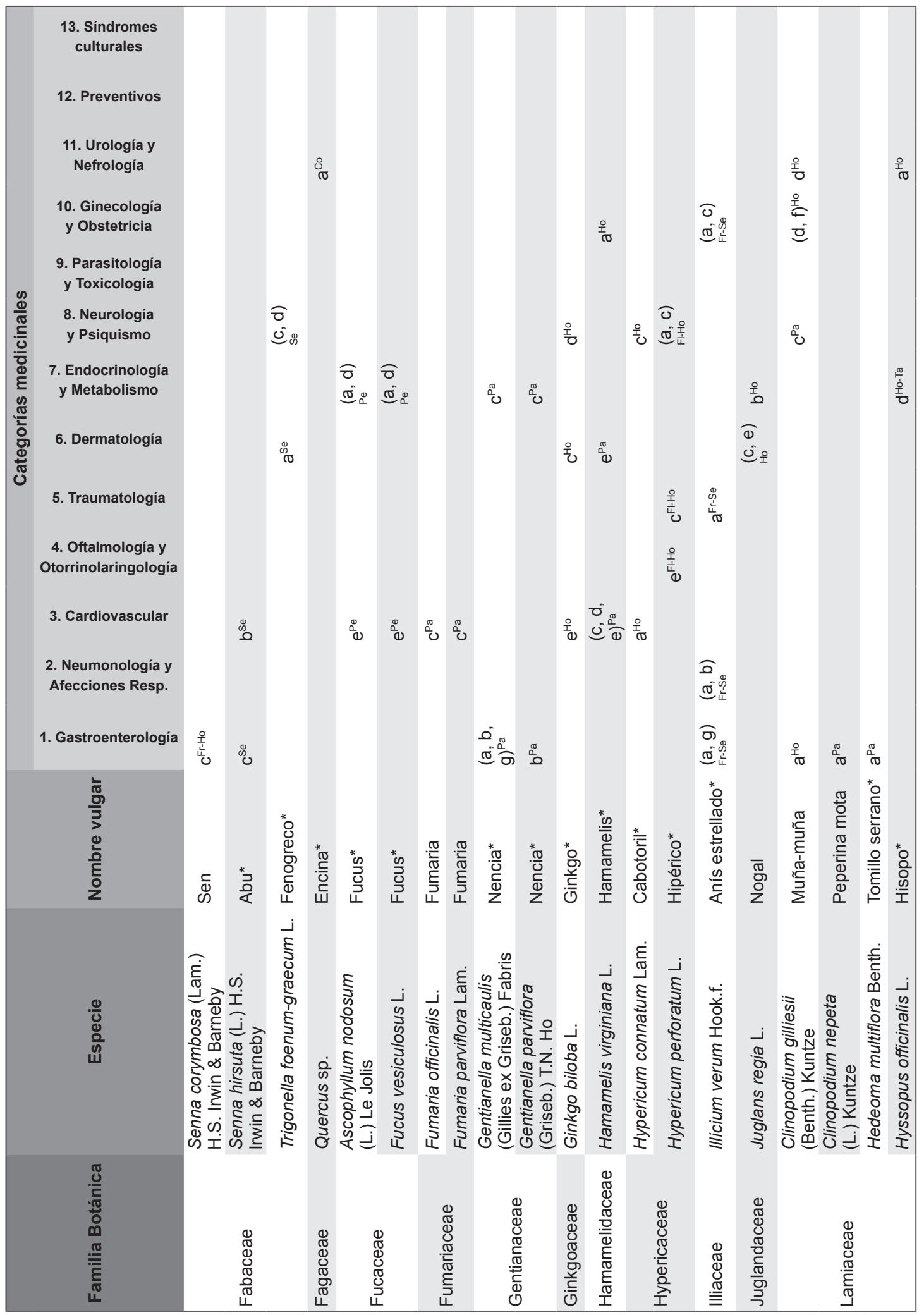


Bol. Soc. Argent. Bot. 52 (4) 2017

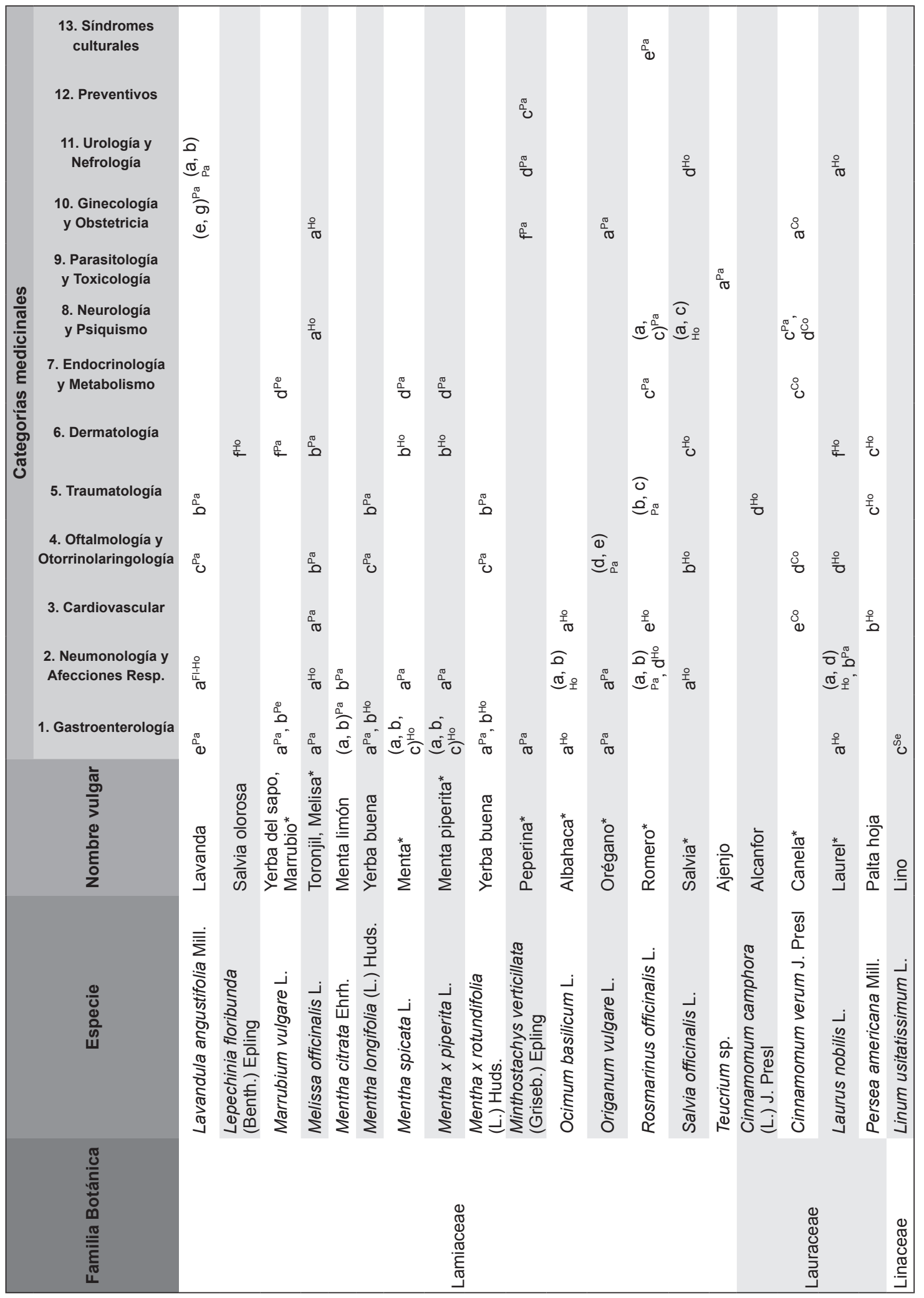




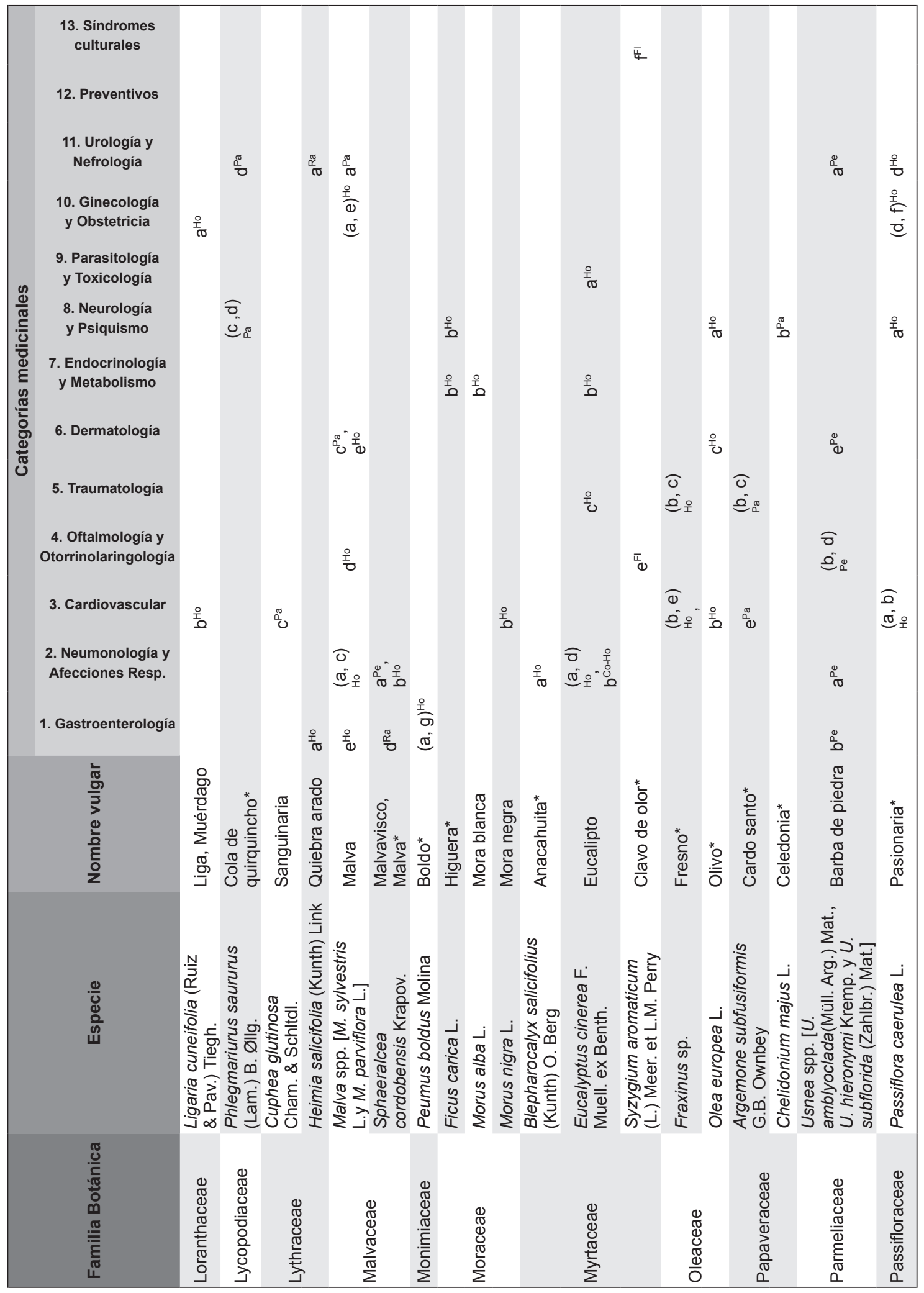


Bol. Soc. Argent. Bot. 52 (4) 2017

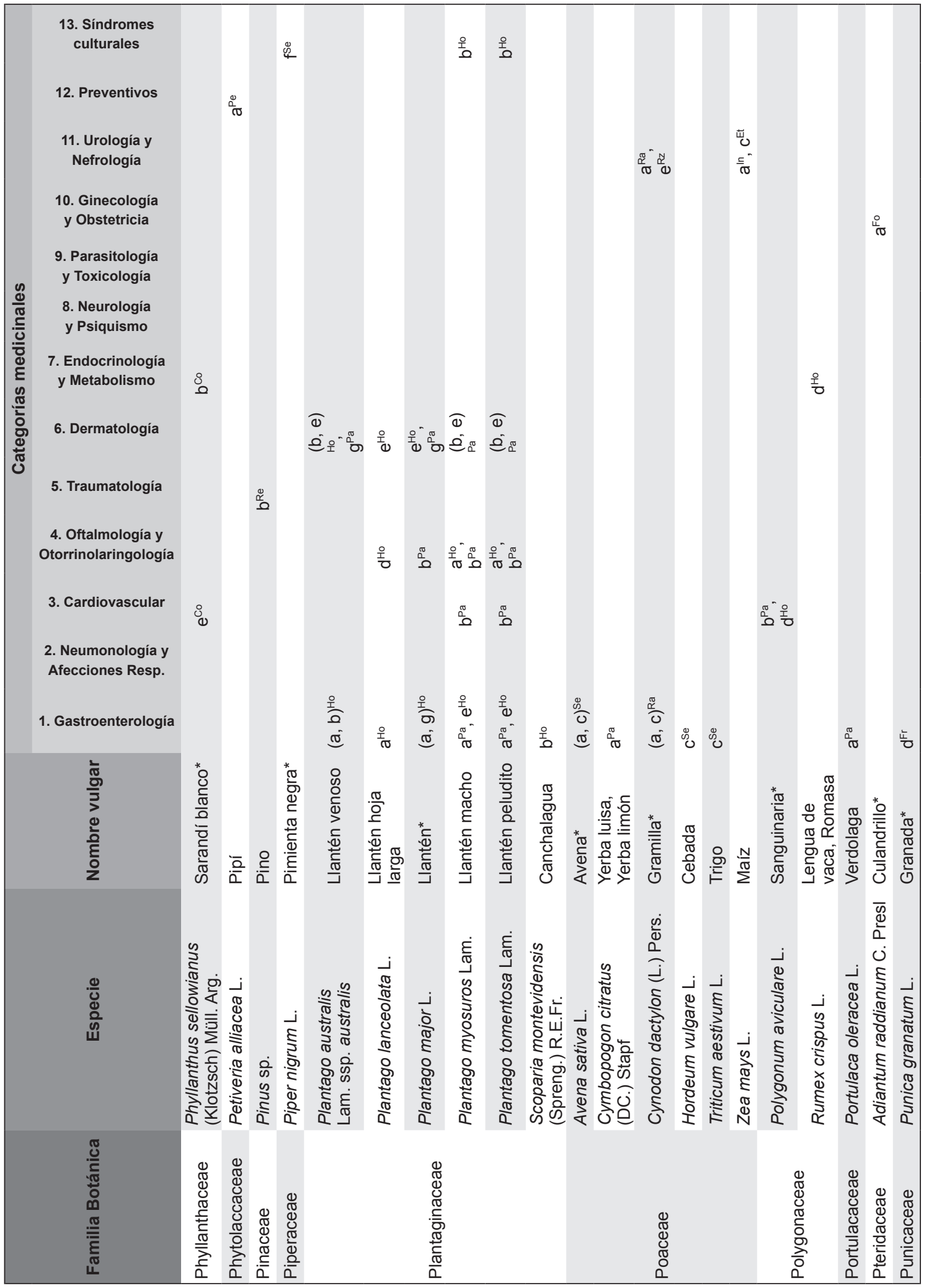


M. C. Luján et al. - Practicantes nativos del Valle de Traslasierra, Córdoba

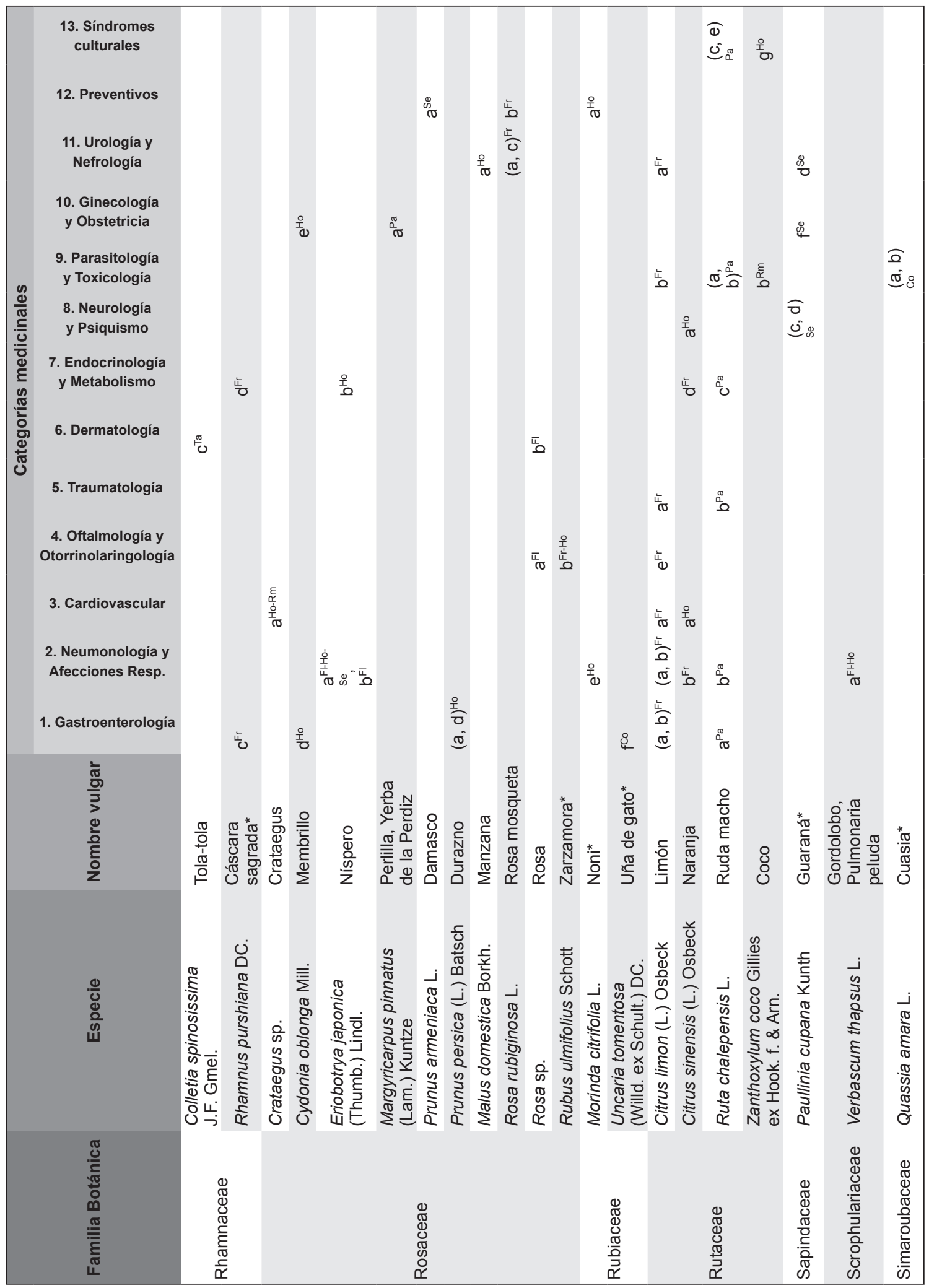


Bol. Soc. Argent. Bot. 52 (4) 2017

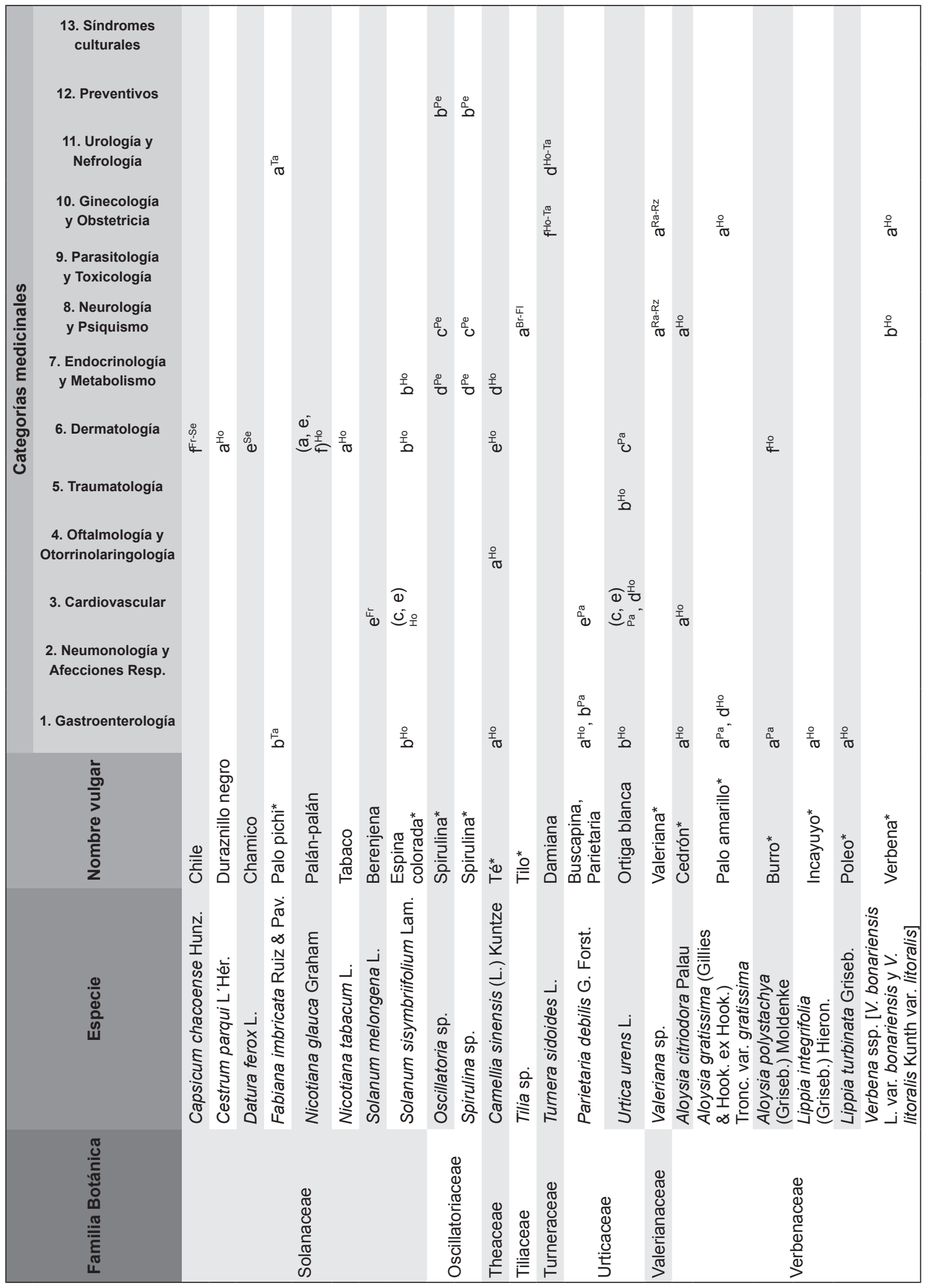



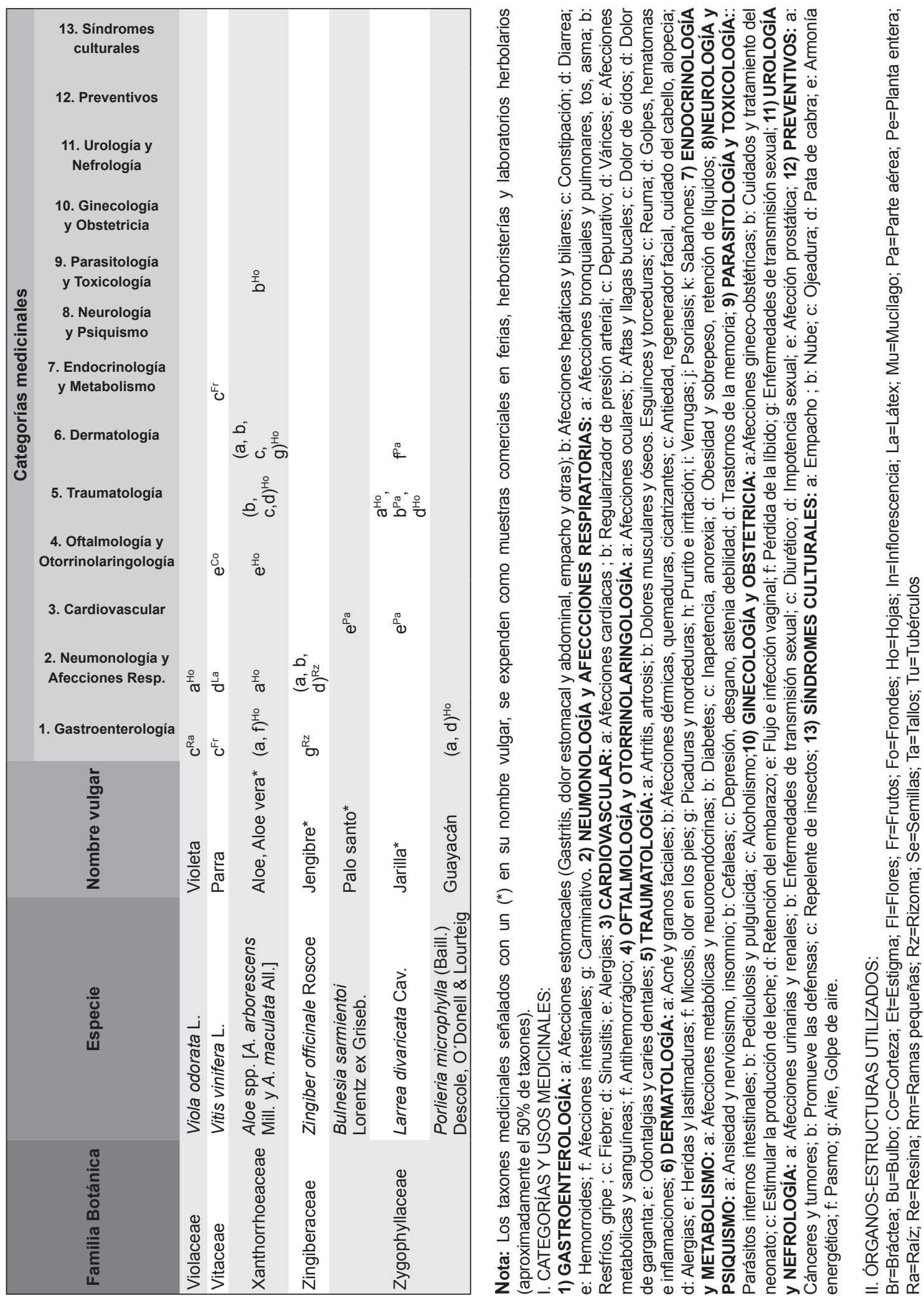
Con respecto a la materia médica, en el Valle de Traslasierra se da también una incorporación de recursos medicinales foráneos asociados al fenómeno de la globalización. Sin embargo, a diferencia de la creciente erosión y pérdida de los conocimientos autóctonos tradicionales señalado para áreas urbanas (Pieroni et al., 2012; Quave et al., 2012), en esta área de estudio se produce un enriquecimiento de las farmacopeas medicinales con la adopción de nuevas especies del mercado y a la vez se mantienen prácticas de recolección de plantas nativas, ya que los ambientes locales aún conservan recursos medicinales autóctonos.

Por otra parte, en lo que concierne a las formas de adquisición del conocimiento Oliveira Abreu et al. (2015), postulan de sus observaciones a campo en el Nordeste de Brasil, que los pobladores nativos adquieren el conocimiento por observación directa, mientras que los migrantes desarrollan una búsqueda activa en la que resultan frecuentes la consulta a fuentes (libros, websites, y otros). Este no es el caso de nuestra área de estudio, en la que algunos especialistas nativos han incorporado un bagaje de saberes desde múltiples fuentes, incluso de los materiales de lectura y medios de comunicación, evidenciando un uso creciente de las MAC.

En lo concerniente a la composición florística de la farmacopea medicinal de esta región, se observa un patrón similar a las de otras regiones del mundo, con un relevante número de especies en las familias Asteraceae, Lamiaceae, Rosaceae, Fabaceae, Solanaceae y Apiaceae (Molares \& Ladio, 2009; Quave et al., 2012). Como lo señalan estas últimas autoras, Asteraceae es la familia con mayor frecuencia de aparición en las floras medicinales Holárticas y del Neotrópico (Moerman et al., 1999; Leonti et al., 2003). Por su parte Lamiaceae y Fabaceae siguen más bien un patrón neotropical (Leonti et al., 2003). Considerando estas familias, se estaría ratificando el patrón global de conocimiento humano que postula Moerman et al. (1999), mediante el cual las poblaciones de diferentes regiones del mundo han seleccionado especies medicinales similares pertenecientes a las mismas familias. Sin embargo, mientras estos autores refieren que la familia Poaceae es una de las menos utilizadas con fines medicinales, en el Valle de Traslasierra ocupa el octavo lugar de importancia. Estos resultados dan cuenta de que la selección de las etnofloras responde, además de los aspectos históricos y culturales antes mencionados, a patrones ecológicos ambientales.

Un aspecto distintivo de esta región, en relación con su etnomedicina, es que resulta habitual la residencia de comunidades terapéuticas rurales asociadas al fenómeno New Age -o de la Nueva Era-, cuyos miembros recurren a un repertorio de terapias, entre las cuales las plantas (medicina herbaria y fitoterapia) ocupan un lugar relevante. En este sentido, los especialistas consultados se encuentran imbricados en los recorridos terapéuticos de diferentes pobladores (nativos y foráneos), conformando lo que Carozzi (2000) da en llamar un "circuito alternativo" con un eclecticismo de prácticas terapéuticas. Consecuencia de ello también, es que los entrevistados de Traslasierra aportan un bagaje más amplio de taxones y saberes provenientes no sólo de otras fuentes y campos del saber, sino también de diferentes actores, siendo para el caso relevante el contacto entre el poblador nativo y el neo-rural. Entre los entrevistados referenciados como pobladores con mayor cantidad de saberes tradicionales de Traslasierra, el saber médico popular transita de la mano de costumbres que implican el uso de los recursos domésticos para aliviar el malestar; sin embargo, estos recursos domésticos no necesariamente son los que se consideran "folklóricos" o enraizados. En coincidencia con Ramallo \& Echenique (2000), se observa que la influencia de los medios de comunicación y las políticas sanitarias medicalizantes han sido un vehículo por el cual han ingresado a los "botiquines familiares" elementos que atienden las dolencias con recursos "avalados" por la medicina alopática y por el discurso publicitario de las empresas alimenticias y farmacológicas. Éstas, a su vez, han "adoptado" de forma sui géneris, las consignas naturistas, a fin de asimilarse a la vida cotidiana de los pobladores. Se observa en este sentido, un conocimiento híbrido, que se ve reforzado en particular en Traslasierra, por la práctica de comercialización y explotación de estos recursos en la dinámica de un mercado global. Aquí lo "híbrido" no sólo sería un conocimiento intermedio o el entrecruzamiento entre dos formas puras (lo moderno y lo tradicional), sino más bien el resultado de la articulación de conocimientos y prácticas locales/regionales y globales (García Canclini, 2012). Las consideraciones de Ayora Díaz (2002) resultan esclarecedoras en este sentido, al señalar cómo "lo híbrido de las medicinas, se 
expresa en las articulaciones y mezclas de los imaginarios que definen cada forma de conocimiento y práctica médica." Otro fenómeno que se observa particularmente en Traslasierra, es el influjo en las concepciones y representaciones locales, del fenómeno de la neo-ruralidad, estrechamente asociado con las migraciones internas. En este sentido, resultan de utilidad explicativa, las observaciones de Trimano (2014), quien visualiza y caracteriza los cambios culturales en la ruralidad de áreas serranas del Valle de Traslasierra, dentro de un contexto sociológico, y percibe a esta zona como escenario de un amplio movimiento de emigración de la ciudad al campo, y como sociedades en las que conviven diversidad de culturas e identidades. $\mathrm{Si}$ se transfiere esta interacción de actores al ámbito de la etnomedicina, se explica la frecuente mixtura de diversas medicinas entre los practicantes emergentes y los practicantes nativos preexistentes. Asimismo, muchas de estos saberes convergen en un mismo practicante. Este proceso, aunque en forma incipiente, fue visualizado previamente por Ramallo $\&$ Echenique (2000) en un estudio antropológico en esta región, en el que intersectan distintas disciplinas relacionadas con las representaciones sociales del proceso salud, enfermedad y atención con énfasis en el saber médico popular especialmente en el grupo de curanderos. Las autoras sostienen que se viene produciendo, hace relativamente poco tiempo, la visibilización de nuevos discursos místicos (del orientalismo y de la vertiente andina) que se conjugan con los principios religiosos del cristianismo. Por esta razón se han introducido en la vida cotidiana de estas comunidades productos y servicios que son "usados" generalmente por la franja poblacional de migrantes, valorizando los recursos naturales para la consecución de la salud. En consonancia han incorporado representaciones del cuerpo desde una perspectiva espiritual en la que involucran prácticas alimenticias, sanitarias, corporales e incluso estructuras edilicias que les permiten resolver sus problemas de manera específica.

En síntesis, se observa que la etnomedicina y la etnobotánica médica del Valle de Traslasierra resulta característica de contextos pluriculturales, a la vez que presenta rasgos ya descriptos para poblaciones migrantes y urbanas (Medeiros et al., 2012; Oliveira Abreu et al., 2015), aunque con las particularidades que le imprimen el influjo de la neo-ruralidad y de las MAC.

\section{Conclusiones}

A manera de síntesis señalaremos que, los practicantes nativos, a la vez de mantener vigente su hacer con base en el saber médico popular, han incorporado representaciones y prácticas terapéuticas variadas, conformando así una vasta farmacopea natural con múltiples significaciones. En esta región se observa junto a las MT, la presencia más o menos influyente de las MAC asociadas al fenómeno New Age, y de los circuitos alternativos; asimismo se da la resignificación de las MT en términos biomédicos, a la vez que cuestionan a la MO. También la composición de la flora medicinal da cuenta de esto, ya que está representada en un $45 \%$ por flora introducida cultivada, con un perfil muy similar al de una etnobotánica urbana. Asimismo, cerca del 50\% de los taxones utilizados en las múltiples medicinas forman parte de la cadena de comercialización en ferias, herboristerías y laboratorios herbolarios, que se expenden procesados como muestras comerciales en tanto otros como medicamentos herbarios. Los principales usos medicinales se destinan al tratamiento de las afecciones gastrointestinales y respiratorias, mostrando similitudes y continuidad en este aspecto, con otras farmacopeas naturales, aunque también se observa comparativamente, una gran riqueza local en cantidad de especies y usos medicinales.

En el marco de esta creciente afición por las plantas introducidas y de amplia difusión en el mercado global, señalamos cómo se visibilizan transformaciones en las farmacopeas nativas debido a la influencia de las MAC - como se observa en el Valle de Traslasierra- lo que nos lleva a pensar a escala regional, en el rol cada vez más relevante y crítico que juega la etnobotánica para el cuidado de la salud en contextos pluriculturales.

\section{Agradecimientos}

A los pobladores del Valle de Traslasierra por su acogida cordial y por los saberes compartidos. A la Lic. Claudia Ramallo por su hospitalidad y sus valiosos aportes para la discusión y el trabajo de campo. Al CONICET, SECyT-UNC, PICT 1633 y PICT 1001 (ANPCyT) por el apoyo económico. 


\section{Biblografía}

ANDERSON, E. N., D. M. PEARSALL, E. S. HUNN \& N. J. TURNER. 2011. Ethnobiology. John Wiley \& Sons Publ., Hoboken, New Jersey.

ARIAS TOLEDO, B. 2006. Aspectos cuantitativos, cualitativos y simbólicos de la medicina tradicional de los pobladores criollos de Cerro Colorado (Córdoba, Argentina). Pinaco Antrop. Cognitiva 5: 105-115

ARIAS TOLEDO, B., L. GALETTO \& S. COLANTONIO. 2007. Uso de plantas medicinales y alimenticias según características socioculturales en Villa Los Aromos (Córdoba, Argentina). Kurtziana 33: 79-88.

AYORA DÍAZ, S. I. 2002. Globalización, conocimiento y poder. Médicos locales y sus luchas por el reconocimiento en Chiapas, Plaza y Valdés, México.

BARBOZA, G. E., J. J. CANTERO, C. O. NUÑEZ \& L. ARIZA ESPINAR (eds.). 2006. Flora medicinal de la provincia de Córdoba (Argentina): Pteridófitas y antófitas silvestres o naturalizadas. Museo Botánico de Córdoba, Argentina.

BARRY, C. A. 2006. The role of evidence in alternative medicine: Contrasting biomedical and anthropological approaches. Soc. Sci. Med. 62: 2646-2657.

BERNARD, H. R. 2006. Interviewing: Unstructured and semistructured. Research methods in Anthropology. Qualitative and quantitative approaches.

CAROZZI, M. 2000. Nueva Era y Terapias alternativas. Construyendo significados en el discurso y la interacción. Educa, Buenos Aires.

CEUTERICK, M., I. VANDEBROEK, B. TORRY \& A. PIERONI. 2008. Cross-cultural adaptation in urban ethnobotany: the Colombian folk pharmacopoeia in London. J. Ethnopharmacol. 120: 342-359.

DOUGLAS, M. 1998. Estilos de pensar. Ed. Gedisa, Barcelona, España.

ERNST, E. 2000. Prevalence of use of complementary/ alternative medicine: a systematic review. Bull.World Health Organ. 78: 252- 257.

FRANCO J. \& C. PECCI. 2003. La relación médicopaciente, la medicina científica y las terapias alternativas. Medicina (B. Aires) 63: 111-118.

GARCÍA CANCLINI, N. 2012. Culturas hibridas. Estrategias para entrar y salir de la modernidad. Paidós, Buenos Aires.

GOLENIOWSKI M., G. BONGIOVANNI, L. PALACIO, C. NUÑEZ \& J. J. CANTERO. 2006. Medicinal plants from the "Sierra de Comechingones", Argentina. $J$ Ethnopharmacol. 107: 324-341.

GORGAS, J. A. \& J. L. TASSILE. 2001. Regiones naturales de la Provincia de Córdoba. Agencia Córdoba Ambiente, Gobierno de la Provincia de Córdoba, Argentina.

GUBER, R. 2004. El salvaje metropolitano: Reconstrucción del conocimiento social en el trabajo de campo. Paidós, Buenos Aires.
HILGERT, N. 2009. La salud en las Yungas. ¿Cuáles son los principales problemas según la medicina tradicional y la formal? En: Vignale N. D. \& M. L. Pochettino (eds.) Avances sobre plantas medicinales andinas, pp. 1-43. RISAPRET/CYTED, Jujuy.

HILGERT, N. \& G. E. GIL. 2008. Los cambios de uso del ambiente y la medicina herbolaria. Estudio de caso en Yungas argentinas. BLACPMA 7: 130-140.

HILGERT, N. I., D. A. LAMBARÉ, N. D. VIGNALE, P. C. STAMPELLA \& M. L. POCHETTINO. 2014. ¿Especies naturalizadas o antropizadas? Apropiación local y la construcción de saberes sobre los frutales introducidos en época histórica en el norte de Argentina. Rev. Biodivers. Neotrop. 4: 69-8.

IDOYAGA MOLINA, A. 2003. Culturas, enfermedades y medicinas. Reflexiones sobre la atención de la salud en contextos interculturales de Argentina. IUNA, Buenos Aires.

LADIO, A. H. \& U. P. ALBURQUERQUE. 2014. The concept of hybridization and its contribution to urban ethnobiology. Ethnobiology and Conservation 3: 6 .

LAGROTTERIA, M. \& M. AFFOLTER. 1999. Sustainable production and harvest of medicinal and aromatic herbs in the Sierras de Córdoba Region, Argentina. In: Nazarea V. (ed.), Ethnoecology. Situated Knowledge/Located lives, pp. 48-72. The University of Arizona Press, Estados Unidos.

LAGROTTERIA, M., M. DIFEO, M. A. TOYA \& R. A. MONTENEGRO. 1986. Situación de plantas medicinales y aromáticas en la provincia de Córdoba. Anales de SAIPA 8: 111-125.

LAGROTTERIA, M. \& M. A. TOYA. 1987. Plantas medicinales y aromáticas del Dpto. de San Javier. Subsec. Gest. Amb., Sec. Min. y Coord., Gob. Pcia. Cba., Argentina.

LEONTI, M., F. R. RAMIREZ, O. STICHER \& M. HEINRICH. 2003. Medicinal flora of the Popoluca, México: a botanical systematical perspective. Economic Botany 57: 218- 230.

LUJÁN, M. C. 2015. Caracterización etnobotánica de las prácticas de medicina humana y veterinaria en poblaciones rurales, suburbanas y urbanas de Córdoba (Argentina). Tesis doctoral. FCEFyN (UNC), Córdoba, Argentina.

MARTIN, G. J. 2000. Etnobotánica. Manual de métodos. Serie "Pueblos y Plantas". Unesco y Royal Botanic Gardens, Kew, Reino Unido, Ed. Nordan Comunidad, Montevideo, Uruguay.

MARTÍNEZ, G. J. 2005. Recolección y comercialización de plantas medicinales en el Departamento Santa María, Provincia de Córdoba. Acta Farm. Bonaerense 24: 75-84.

MARTÍNEZ, G. J. 2007. Medicinal plants used by the 'Criollos' of Calamuchita (Córdoba, Argentina) to treat 
blood, cardiovascular and neuroendocrinous diseases. J. Herbs Spices Med Plants 13: 22-54.

MARTÍNEZ, G. J. 2008a. Tradicional practices, beliefs and uses of medicinal plant in relation to the maternal-infant health of the Criollo woman in Central Argentina. Midwifery 24: 490-502.

MARTÍNEZ, G. J. 2008b. La farmacopea natural y el tratamiento de las afecciones de la piel en la medicina tradicional de los campesinos de las sierras de Córdoba, Argentina. Dominguezia 24: 27-46.

MARTÍNEZ, G. J. 2010. Las plantas en la medicina tradicional de las sierras de Córdoba. Un recorrido por la cultura campesina de Paravachasca y Calamuchita. Ed. Copista. Córdoba. Argentina.

MARTÍNEZ, G. J. \& A. M. PLANCHUELO. 2003. La medicina tradicional de los criollos campesinos de Paravachasca y Calamuchita, Córdoba (Argentina). Scr. Ethnol. 25: 83-116.

MEDEIROS, P. M, G. TABOADA SOLDATI, N. LEAL ALENCAR, I. VANDEBROEK, A. PIERONI, N. HANAZAKI, U. P. ALBUQUERQUE. 2012. The Use of Medicinal Plants by Migrant People: Adaptation, Maintenance, and Replacement. Evid-Based Compl. Alt. Med. 2012: 1-11

MENSEGUEZ, P., L. GALETTO \& A. M. ANTON. 2007. El uso de plantas medicinales en la población campesina de El Puesto (Córdoba, Argentina). Kurtziana 33: 89-102.

MOERMAN, D. E., PEMBERTON, R. W., D. KIEFER \& B. BERLIN. 1999. A comparative analysis of five medicinal floras. J. Ethnobiol. 19: 49-67.

MOLARES, S. \& A. LADIO. 2009. Ethnobotanical review o the Mapuche medicinal flora: Use patterns on a regional scale. J. Ethnopharmacol. 122: 251-260.

NÚÑEZ, C. O. \& J. J. CANTERO. 2000. Las plantas medicinales del Sur de la Provincia de Córdoba. Fundación Universidad Nacional de Río Cuarto, Córdoba, Argentina.

OLIVEIRA ABREU de, D. B., F. R. SANTORO, U. P. de ALBUQUERQUE, A. H. LADIO \& P. MUNIZ de MEDEIROS. 2015. Medicinal plant knowledge in, a context of cultural pluralism: A case study in Northeastern Brazil. J. Ethnopharmacol. 175: 124-130.

OMS. 2008. Subsanar las desigualdades en una generación. Resumen analítico. Disponible en: http://whqlibdoc. who.int/hq/2008/WHO_IER_CSDH_08.1_spa.pdf [Acceso: 02-03-2012].

OMS. 2014. Estrategia de la OMS sobre medicina tradicional 2014-2023. Disponible en: http:// www.paho.org/per/index.php?option $=\mathrm{com}$ d o c man \& vi e w = d own load \& c a te gory slug=presentaciones-648\&alias [Acceso: 07-042017].

PIERONI, A. \& C. L. QUAVE. 2005. Traditional pharmacopoeias and medicines among Albanians and Italians in southern Italy: a comparison. $J$. Ethnopharmacol. 101: 258-270.

PIERONI, A., C. L QUAVE, M. E GIUSTI, \& N. PAPP. 2012. "We are Italians!": the hybrid ethnobotany of a Venetian diaspora in Eastern Romania. Human Ecology 40: 435-451.

PIKE, K. L. 1972. Puntos de vista émicos y éticos para la descripción de la conducta. En: Smith A. G. (ed.), Comunicación y cultura I. La teoría de la comunicación humana, pp. 233-248, Buenos Aires.

POCHETTINO, M. L., P. ARENAS, D. SÁNCHEZ \& R. CORREA. 2008. Conocimiento botánico tradicional, circulación comercial y consumo de plantas medicinales en un área urbana de Argentina. BLACPMA 4: 141-148.

QUAVE, C. L., M. PARDO-DE-SANTAYANA \& A. PIERONI. 2012. Medical ethnobotany in Europe: from field ethnography to a more culturally sensitive evidence-based CAM?. Evid-Based Compl Alt. 17 pag.

RAMALLO, A. C. \& M. D. ECHENIQUE. 2000. Representaciones sociales de salud, enfermedad y atención en el saber médico popular (curanderismo) en poblaciones del Valle de Traslasierra. Tesina en Psicología de la Universidad Nacional de Córdoba, Córdoba, Argentina.

SCARPA, G. F. 2007. Etnobotánica de los criollos del oeste de Formosa: Conocimiento tradicional, valoración y manejo de las plantas forrajeras. Kurtziana 33: 153174.

SCARPA, G. F. 2012. Las plantas en la vida de los criollos del oeste formoseño: medicina, ganadería, alimentación y viviendas tradicionales. Asociación Civil Rumbo Sur, Buenos Aires.

STURTEVANT, W. C. 1964. Studies in Ethnoscience. American Anthropologist 66: 99-131.

TRILlO, C., B. ARIAS TOLEDO, L. GALETTO \& S. COLANTONIO. 2010. Persistence of the use of medicinal plants in rural communities of the Western Arid Chaco (Córdoba, Argentina). Open Complement Med J. 2: 80-89.

TRILLO, C., S. COLANTONIO \& L. GALETTO. 2014. Perceptions and use of native forests in the arid Chaco of Córdoba, Argentina. Ethnobot. Res. Applications 12: 497-510.

TRIMANO, L. G. 2014. Las condiciones formales del cambio cultural en la ruralidad. El análisis de un caso en el Valle de Traslasierra, Córdoba, Argentina. Question 1: 81-90.

Recibido el 21 de diciembre de 2016, aceptado el 15 de mayo de 2017. 
